Article

\title{
Deciphering the Manufacturing Production Space in Global City-Regions of Developing Countries-a Case of Pearl River Delta, China
}

\author{
Bo Liu ${ }^{1,2}$, Desheng Xue ${ }^{1,2}$ and Yiming Tan $1,2, *$ (D) \\ 1 Guangdong Provincial Key Laboratory of Urbanization and Geo-simulation, School of Geography and \\ Planning, Sun Yat-Sen University, Guangzhou 510275, China; lovise0926@163.com (B.L.); \\ eesxds@mail.sysu.edu.cn (D.X.) \\ 2 Southern Marine Science and Engineering Guangdong Laboratory (Zhuhai), Zhuhai 519000, China \\ * Correspondence: tanym7@mail.sysu.edu.cn
}

Received: 5 November 2019; Accepted: 28 November 2019; Published: 2 December 2019

\begin{abstract}
In the context of economic globalization, the manufacturing production space in the global city-regions of developing countries have presented significant spatial characteristics, attracting attention to the problems of intensive and sustainable development of production space. Taking global city-region in the Pearl River Delta (PRD) as an example, manufacturing production space based on remote sensing (RS) technology and point of interest (POI) data extraction was more precise and continuous, which had more advantages for further analysis of spatial characteristics and influencing factors in multi-scale, and precise policy recommendations. The results show that: (1) under different scales, the distribution characteristics of manufacturing production space and the agglomeration characteristics of spatial form are different. It is not simply extensive agglomeration or diffusion that can accurately explain its diversified spatial characteristics. Meanwhile, for the local manufacturing production space optimization control, the local government should apply advanced experience according to local conditions instead of simply and roughly promotion or containment. (2) Influencing factors show a strong positive correlation with the urbanization rate, the number of foreign direct investment (FDI) enterprises and gross industrial production, and which shows a weak negative correlation with fixed asset investment and the employment population. In conclusion, the spatial characteristics of manufacturing production space in global city-regions in developing countries is significantly different from that in Western countries, and its influencing factors have similarities and differences. Therefore, when conducting multi-scale space optimization and sustainable regulation, the government should consider more about the actual multi-scale spatial characteristics of manufacturing production space and its influencing factors instead of copy the Western experience.
\end{abstract}

Keywords: manufacturing production space; geographically weighted regression; point of interest; multi-scale spatial patterns; remote sensing technology

\section{Introduction}

With the global spread of manufacturing, the elements of globalization dominated by advanced producer services are concentrated in the world cities [1,2], and some specialized and standardized manufacturing sectors are spreading to larger regional scales by means of advanced transportation logistics and communication technologies [3,4], which have gradually formed a highly integrated multi-center, multi-level global city-region centered on an international metropolis [5-7]. Currently, the industrial space within the global city-regions in western countries has entered the 
post-industrialization stage. A large number of scholars have kept a close eye on the phenomenon that the main economic activities such as advanced producer services (APS), knowledge-intensive industries, and innovative industries are reshaping the regional spatial structure in the context of the rise of knowledge economy [8-11]. However, in the global city-regions of developing countries, industrialization and deindustrialization are going on at the same time [12,13]. The paths of regional integration into economic globalization are not the same, and the regional spatial structure presents differences and typicality. Scholars mainly focus on the fact that headquarters economy, producer APS, foreign direct investment (FDI), or foreign-funded manufacturing industry, as the leading industries, have an important impact on regional economic development and regional spatial structure [14-19]. The spatial reconstruction of the manufacturing industry is still the key variable for shaping the spatial structure of the global city-regions of developing countries [20]. However, there is not enough attention paid to other types of manufacturing industries besides foreign-funded manufacturing industry. Therefore, it is necessary to study the development of manufacturing industry in the global city-region of developing countries. The first aim of this paper is to improve public understanding of manufacturing spatial distribution characteristics and influencing factors in the global city-regions of developing countries.

On the other hand, in the context of economic globalization, manufacturing industry was always playing an important role in shaping the spatial structure of the city-regions. In the past, scholars studied the spatial distribution of manufacturing industry in city-regions of western countries, mainly based on the metropolitan scale to explore the location selection mode of FDI enterprises [21], the spatial distribution characteristics of industrial activities [22-24] or different types of manufacturing industry [25] and their influencing factors, etc. More recently, with the deepening development of economic globalization, manufacturing space has spread to a larger region, such as the global city-regions of developing countries $[5,26]$. Therefore, it is of great significance to explore the differences of manufacturing spatial distribution characteristics and influencing factors between developing countries and Western countries at the scale of global city-region. The second aim of this paper is to improve public understanding of the similarities and differences of manufacturing spatial distribution characteristics and its influencing factors in global city-regions between developing countries and Western countries.

However, based on the perspective of industrial development, several scholars have paid much attention to the spatial agglomeration characteristics of different types of manufacturing industry in the city-regions of developing countries $[27,28]$. Furthermore, the mainstream researches on the spatial agglomeration characteristics of manufacturing industry mainly focus on making use of economic census data, manufacturing industry data in the industrial sector, or data on the employment of the manufacturing industry, taking urban [29-31] or urban internal streets or districts [32-34] as statistical units, in order to construct the industrial space of manufacturing industry. However, such kinds of researches are mainly based on the economic statistics and enterprise attribute data to construct the manufacturing industry space that are not accurate enough, and the spatial continuity is not good enough, either. Therefore, it could not guide local industrial policy and urban spatial planning precisely and appropriately [35]. In recent years, with the rapid development of remote sensing (RS) and geographic information system (GIS) technology, it is possible to obtain large-scale spatial information accurately and continuously. Scholars mainly explore the land use change and spatial evolution process in city-regions by means of these spatial analysis methods [36-39]. Few scholars have also made use of RS and GIS technology to conduct relevant explorations on the spatial characteristics of industrial production space $[40,41]$, the spatial and temporal evolution of industrial production space and its driving mechanism [42]. However, the industrial production space includes a large area of mining, electricity, heat, gas and water production and supply, and construction industry, which cannot characterize the spatial state of regional real economic production activities more accurately. Using remote sensing technology and the point of interest (POI) data, a large area of urban ground objects can be accurately extracted [43-46]. Therefore, using RS and GIS technology to extract spatial 
information of manufacturing industry, and combining the POI data of manufacturing enterprises to obtain attribute information of manufacturing enterprises, then separating the manufacturing production space from the industrial production space, and exploring the spatial structure and spatial form characteristics of the manufacturing entities in the city-regions need to be strengthened.

The manufacturing production space is the implementation of manufacturing activities and manufacturing sectors in the geographical space. Its spatial characteristics not only reflect the evolution of the spatial pattern of production activities as well as its physical elements in the historical period, but also influences the future direction of regional economic space [47]. The global city-regions have the function of the regional production platform with global market competitiveness [5], but the fine layout of the manufacturing production space within the region is still not clear [6]. Therefore, it is of great significance to select the advanced local production platform of developing countries as the case area to explore the distribution characteristics and influencing factors of the regional manufacturing production space. As an advanced territorial platform for China to integrate into economic globalization, the research of Pearl River Delta (PRD) has always attracted much attention from scholars [48,49]. At the current stage, there is a new phenomenon of manufacturing enterprises moving out and moving in of the global city-region of the PRD [17]; these will lead to a new round of reconstruction of manufacturing production space. Meanwhile, since the financial crisis of the year of 2008, with tension and rising labor costs, land resource issues of emergency resource environmental bearing capacity is increasingly serious, the 18th National Congress of the Communist Party of China has put forward that production space should be intensive and efficient. The manufacturing production space, as an important part of city-region function space and contradiction problem of the most prominent areas, the optimal control is extremely urgent [50,51]. Accurately identifying and analysing the true and continuous distribution of manufacturing production space in the city-region is the basis for optimizing the regulation and promoting the intensive, efficient and sustainable development $[43,52]$. Therefore, the third aim of this paper is to guide the formulation of intensive regulation and control policies of manufacturing production space according to the agglomeration characteristics of manufacturing production space under different spatial scales based on the local development background — not only meeting the national/regional development program, but also promoting the sustainable development of local economy and production space.

The structure of the manuscript is as follow: First, this study made use of RS and GIS technology and combined POI data of manufacturing enterprises to conduct accurate identification and extraction the entity information of production space of manufacturing industry through high-resolution Google Earth images. Second, the spatial analysis of mathematical statistics and exponential models were conducted to conduct an analysis of the manufacturing production space characteristics of the PRD under different spatial scales. Finally, the geographically weighted regression (GWR) model was introduced to further explore the spatial heterogeneity of the main influencing factors of manufacturing production space in the PRD counties (districts), so as to provide planning reference for the sustainable development and optimization of manufacturing production space in global city-region of the PRD in the future.

\section{Data and Material}

\subsection{Study Area and Data}

\subsubsection{Study Area}

Located on the southern coast of mainland China (Figure 1), the PRD is one of China's most typical export-oriented economic areas and has become one of China's most typical global city-regions [16,53]. Since the high development of economic globalization, the output value of the secondary industry in the PRD has kept a significant upward trend, and its proportion in gross domestic product (GDP) has been maintained at more than $42 \%$ (Table 1) [54]. In accordance with the newly revised PRD regional plan (2014-2020), the PRD covers 11 cities, including Hong Kong (HK), Macao (MC), Guangzhou (GZ), 
Zhuhai (ZH), Shenzhen (SZ), Foshan (FS), Jiangmen (JM), Dongguan (DG), Zhongshan (ZS), Huizhou (HZ), and Zhaoqing (ZQ) with an area of $54,764.6 \mathrm{~km}^{2}$ in 2012. The empirical data in this study do not include $\mathrm{HC}$ and $\mathrm{MC}$, because of limitation of data statistical caliber.

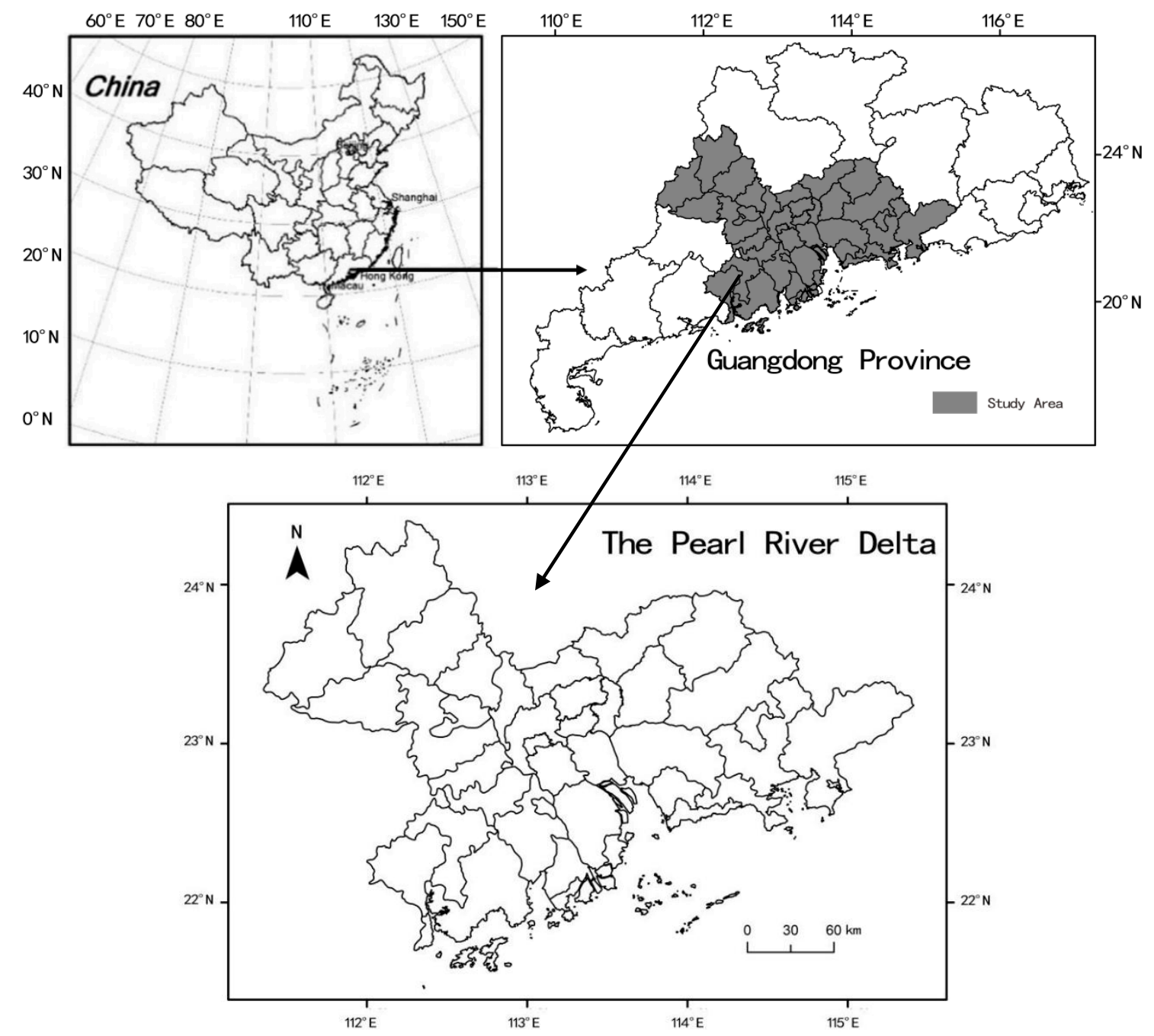

Figure 1. Location of study area.

Table 1. Pearl River Delta's (PRD's) economic profile.

\begin{tabular}{cccc}
\hline Year & GDP (100million yuan) & Secondary industry (100million yuan) & Proportion of GDP \\
\hline 1990 & 1006.88 & 441.65 & $44 \%$ \\
2000 & 8471.28 & 4044.38 & $48 \%$ \\
2010 & 38377.06 & 18761.56 & $49 \%$ \\
2017 & 75710.14 & 31542.82 & $42 \%$ \\
\hline
\end{tabular}

\subsubsection{Data}

The high-resolution Google Earth image data came from the 15th grade 4.78 meters current image (buildings can be seen clearly) obtained by the Google satellite map downloader in May 2017. 
The POI data were obtained from application programming interfaces (API) provided by Gaode Map API (http://lbs.amap.com/) in May 2017. The POI data include diversified types, such as education, entertainment, industrial, etc. We selected the manufacturing enterprises' POI data from the industrial type. Among them, the selection criteria of types of manufacturing enterprises refer to "classification of national economy industries" (GB/T4754-2017) (http://www.stats.gov.cn/). Therefore, when extracting the production space and POIs types of manufacturing enterprises in this study, they were all secondary industries, excluding mining (excluding mining auxiliary activities), electricity, heating power, gas and water production and supply, construction, and other industries. At last, we selected the manufacturing companies' POI of the PRD, including 60,114 records, and each manufacturing enterprises' POI records had six attributes' values: city code, enterprise name, address, telephone number, $\mathrm{x}$-coordinates and y-coordinates.

Statistical data related to socio-economic conditions were collected from the Guangdong Statistical Yearbook 2018 [54], and the list of industrial and commercial enterprises were collected from this website (http://www.pu-zi.com/).

\subsection{Remote Sensing Interpretation of Manufacturing Production Space}

In order to ensure the accuracy of the interpretation results in this study, they were interpreted in two types. The first type, the manufacturing enterprises' POI data, were vectorized and extracted from various industrial parks, a large number of scattered industrial zones, independent factories, and township factories. The ground objects extracted in this section presented the texture and spectral characteristics of a typical manufacturing production space, and most of them could be clearly identified. For the areas that were difficult to identify or difficult to determine, they could be corrected and supplemented by the latest Baidu map or field survey, and this part was called the vectorized area.

The second type, there were many manufacturing enterprises' POI data on the ground objects, but the ground objects were too small to be visually interpreted and they did not show the texture and spectral characteristics of typical manufacturing production space, which was called the standardized area. The area was calculated in accordance with the number of POIs multiplied by the unit pixel size of $22.85 \mathrm{~m}^{2}$ (namely, $4.78 \mathrm{~m} \times 4.78 \mathrm{~m}$ ).

The sum of the two types was the overall layout of manufacturing production space in the PRD. Although this method had a large amount of data and was time-consuming, the extracted production space of manufacturing industry was basically close to its actual distribution, whose accuracy and efficiency were better than that of general computer automatic interpretation. Meanwhile, the accuracy of the interpretation was checked through Baidu online map correction, site survey, and related planning data comparison.

Based on the manufacturing enterprises' POI data of the PRD and the 2017 PRD high-resolution Google Earth image, we extracted manufacturing production space by visual interpretation. The detailed interpretation process was shown in the Figure 2.

Firstly, we corrected the high-resolution Google Earth image and administrative division vector map through ENVI software so as to make the error of image correction be controlled within half a pixel. Secondly, the rectification image was imported into ArcGIS10.2 and the manufacturing enterprises' POI data were also imported. Third, we conducted vectorized extraction of manufacturing production space by means of artificial interpretation and visual interpretation. Finally, we extracted the spatial data of manufacturing production space in the Pearl River Delta (shown in the Figure 3), and the total area (the sum of the two types) of the manufacturing production space in the PRD was $1953.84 \mathrm{~km}^{2}$. 


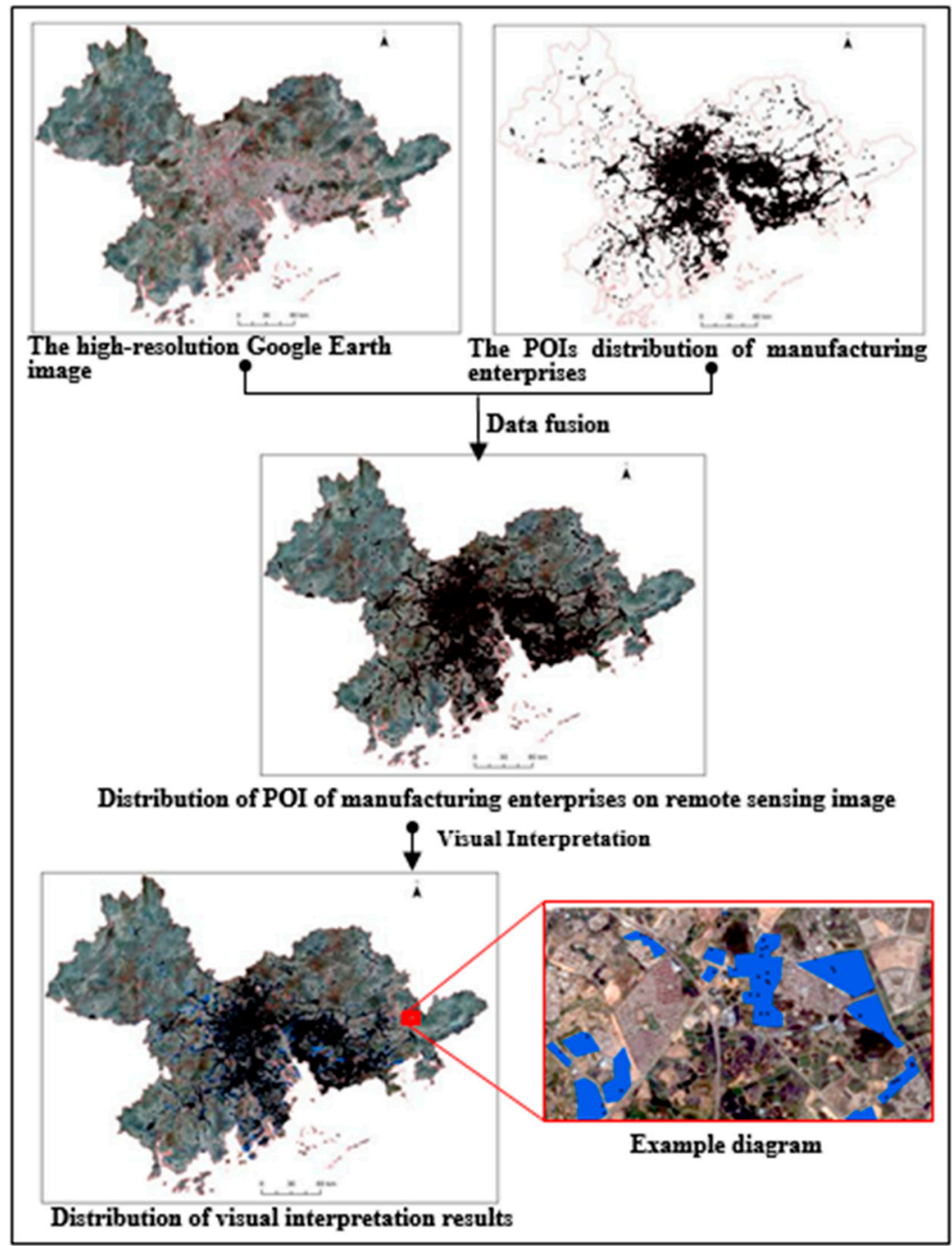

Figure 2. Technique flowchart.

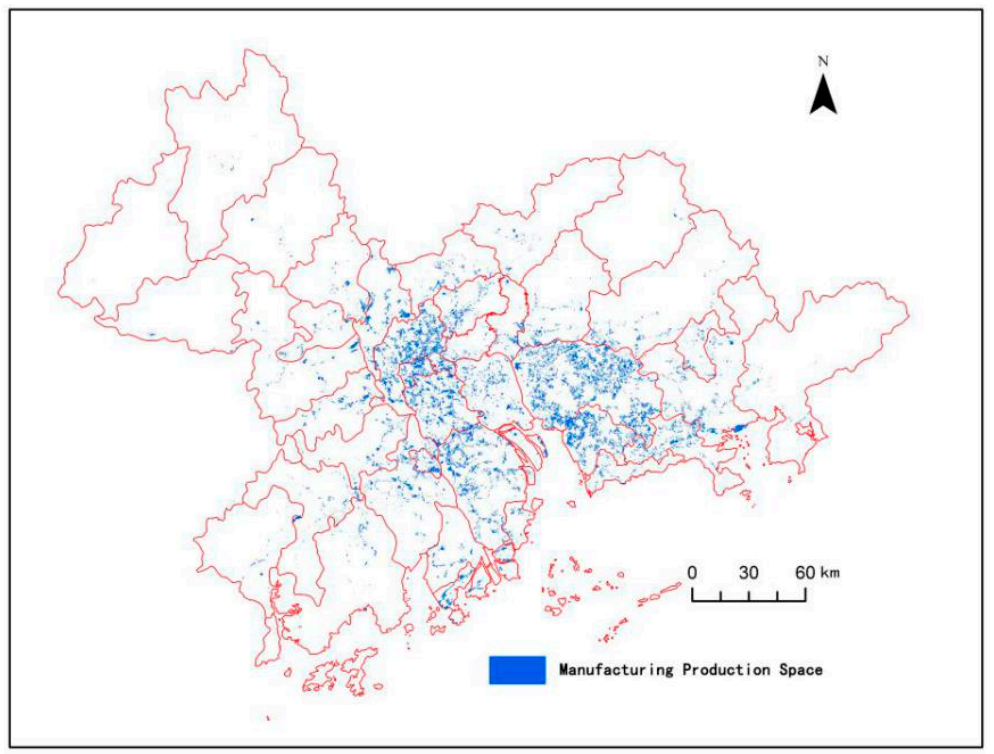

Figure 3. Interpretation results of manufacturing production space in the PRD in 2017. 


\section{Methodology}

\subsection{Spatial Feature Analysis Method}

Specific types of landscape index and spatial feature model were selected to conduct analysis of the spatial characteristics of manufacturing production. The stability index, form compactness, density index, and nuclear density index were selected to comprehensively analyze the form and agglomeration characteristics of manufacturing space in global urban areas of the PRD.

\subsubsection{Stability Index}

Currently, fractal theory is widely used to study urban regional spatial form, urban land use fractal and other aspects [55]. Therefore, this paper introduces fractal dimension to conduct quantitative analysis the morphological characteristics of manufacturing production space. Fractal dimension can not only reflect the complexity of land boundary shape, but also reflect the fragmentation degree of land and the spatial filling ability of graph [56]. In general, fractal dimension is calculated in accordance with the relationship between patch circumference and area, and the relational expression is as follows [57]:

$$
\ln A=\frac{2}{D} \ln P+C
$$

In the equation (1): $A$ is the patch area of industrial production space; $P$ is the total perimeter of the plaque; $C$ is a constant (intercept); and $D$ is the fractal dimension. The theoretical value of the $D$ value is 1.0-2.0. The larger $D$ value is, the more complex the shape of vector patches is and the more irregular the boundary is, and vice versa. When $D=1.5$, it means that the vector plaque is in the Brownian random motion state. The closer it is to this value, the worse its stability will be. Based on this, the stability index $S K$ of manufacturing production space can be defined as follows [58]:

$$
\mathrm{SK}=|1.5-D|
$$

In the equation (2): the theoretical value of $S K$ is $0-0.5$. The larger the value of $S K$, the more stable in the manufacturing production space, and vice versa.

\subsubsection{Form Compactness Index}

Form compactness is considered as a very important concept in reflecting the spatial form of urban regional features $[59,60]$. Scholars used the compactness index to measure the intensive degree of urban land and connected it with the sustainable planning of the urban environment [61-63].

$\mathrm{CI}$ is the compactness index reflecting the compactness of plaque distribution. The larger the CI, the more compact of the spatial pattern of manufacturing production $[59,64]$. On the contrary, it is more dispersed; in the equation, $S_{j}$ represents the plaque area, while $P_{j}$ represents the plaque perimeter.

$$
\begin{gathered}
\mathrm{CI}=\sqrt{\sum_{j=1}^{n} S_{j} / \sum_{j=1}^{n} P_{j}} \\
(\mathrm{j}=1,2, \ldots, \mathrm{n})
\end{gathered}
$$

\subsubsection{Density Index}

Human-dominated land uses, and especially the intensity of the uses, can affect adjacent ecological communities through direct, secondary, and cumulative impacts. Using land use data and a development-intensity measure derived from ecological resources use per unit area, an index of landscape development intensity can be calculated to estimate the potential impacts from human-dominated activities [65]. 
Density index is an index reflecting the intensity of land and space development, which has been used to guide urban spatial planning [43] and sustainable development of urban ecosystem $[66,67]$. In this study, the density index is the ratio of the production space area of the manufacturing industry to the total area of the urban built-up area, which reflects the development intensity of the manufacturing production space. The calculation formula is as follows:

$$
\rho=\left(A / A_{0}\right) \times 100 \%
$$

In the equation (4): $\rho$ is the density index; $A$ is the manufacturing production space area; and $A_{0}$ is the total area of the urban built-up area.

\subsubsection{Kernel Density}

The kernel density estimation method is suitable for visual representation of spatial point patterns, and this method studies the distribution characteristics of points by examining the spatial variation of the point density in the regular area [68,69]. Kernel density analysis tools in arcGIS10.2 is used to calculate the density of elements in their surrounding neighborhoods. In this stud, through this index, we could measure the agglomeration characteristics of manufacturing production space. The calculation equation is as follows:

$$
\hat{\lambda}_{h}(p)=\sum_{i=1}^{n} \frac{3}{\pi h^{4}}\left(1-\frac{\left(p-p_{i}\right)^{2}}{h^{2}}\right)^{2}
$$

In the equation (5): $\mathrm{p}$ is the position of the point to be estimated, $p_{i}$ is the point within the circle with $P$ as the center and $h$ as the radius. In practical application, the value of $h$ is elastic, and it needs to be tested according to different $h$ values.

\subsection{Regression Model Construction}

The formation of the spatial pattern of manufacturing production space was the result of the combined effects of multiple factors. Using for reference of scholars' research on manufacturing space reconstruction and the study of its influencing factors [31,70], the quantitative research on industrial production spatial characteristics $[43,44]$ combines with the industry characteristics of the PRD manufacturing industry [17], in this study the analysis framework shown in the Figure 4 was constructed. Furthermore, taking 37 counties (districts) in the PRD as statistical units, the leading factors affecting the spatial pattern of manufacturing production space in the PRD were analyzed by constructing regression model.

\subsubsection{Variable Selection}

This study constructed an analytical framework of influencing factors (Figure 2), which took the counties (districts) of the PRD as the statistical unit, and the dependent variable selected the area of the manufacturing production space of each county (district). The selection of the independent variable indexes was based on the three production factors, capital [70], labor [71], and land [71] that were dominant in the analysis framework of Figure 4. Selection was also based on other controlling variables, such as urbanization rate and gross industrial production [60,72]. In sum, the statistical data were collected in these four dimensions (Table 2). 


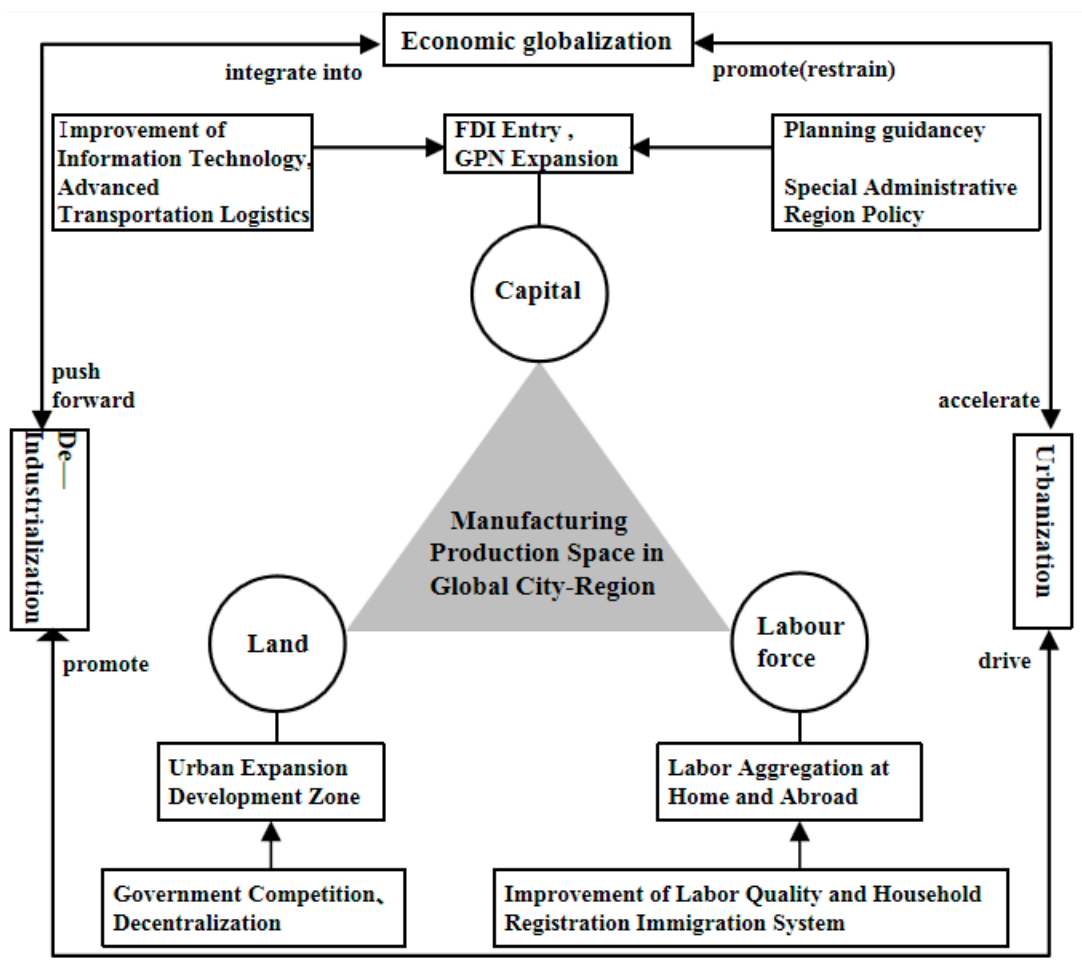

Figure 4. Analysis framework of the influencing factors of manufacturing production space layout.

Table 2. Independent variable selection and its index system test results.

\begin{tabular}{|c|c|c|c|}
\hline Dimension & Index System & Data Sources & OLS test results \\
\hline \multirow[t]{2}{*}{ Capital } & $\begin{array}{l}\text { Number of FDI } \\
\text { enterprises }\end{array}$ & Chinese industrial enterprise database & Good correlation $\sqrt{ }$ \\
\hline & Fixed asset investment & Guangdong Statistical Yearbook 2018 & Good correlation $\sqrt{ }$ \\
\hline \multirow{2}{*}{ Labor } & Employment population & Guangdong Statistical Yearbook 2018 & Good correlation $\sqrt{ }$ \\
\hline & Average annual wage & Guangdong Statistical Yearbook 2018 & Collinearity $\times$ \\
\hline \multirow{3}{*}{ Land } & Land price & $\begin{array}{l}\text { The average level of each county } \\
\text { (district) }\end{array}$ & Poor correlation $x$ \\
\hline & & Impervious surface data & \\
\hline & Built-up area & $\begin{array}{l}\text { (http://www.geosimulation.cn/ } \\
\text { GlobalUrbanLand.html) }\end{array}$ & Collinearity $\times$ \\
\hline \multirow{2}{*}{ Others } & Urbanization rate & Guangdong Statistical Yearbook 2018 & Good correlation $\sqrt{ }$ \\
\hline & $\begin{array}{l}\text { Gross industrial } \\
\text { production }\end{array}$ & Guangdong Statistical Yearbook 2018 & Good correlation $\sqrt{ }$ \\
\hline
\end{tabular}

A total of eight indicators data of each county (district) were collected. Spatial analysis module of OLS Model was conducted through ArcGIS10.3, the model space analysis module eliminated indicators of collinearity and low correlation, and finally five indicators were screened out, such as urbanization rate, fixed asset investment, number of FDI enterprises (enterprises with sales of more than 20 million yuan), gross industrial production, and the employment population.

\subsubsection{Regression Model Construction}

From the perspective of geospatial space, regional economic space development is prone to spatial correlation and spatial heterogeneity. When conducting regression analysis of influencing factors, the parameters of ordinary linear regression equations vary with geographic location, while the geographically weighted regression (GWR) model embeds the geographical position of each statistical unit data into the regression parameters. So, the spatial heterogeneity of each influencing factor can be 
analyzed, which is more conducive to effective and comprehensive excavation of the information that influences the production space of the regional manufacturing industry [73,74]. The GWR model is as follows:

$$
y_{i}=\beta_{0}\left(\mu_{i}, v_{i}\right) x_{i k}+\sum_{k=1}^{p} \beta_{k}\left(\mu_{i}, v_{i}\right) x_{i k}+\varepsilon_{i} \mathrm{i}=1,2, \ldots, \mathrm{n}
$$

In the Equation (5), $\left(u_{i}, v_{i}\right)$ is the latitude and longitude coordinate of city $i ; \beta k\left(u_{i}, v_{i}\right)$ is the parameter to be estimated of the $k$ th independent variable of city $i, x_{i k}$ is the explanatory variable; $\varepsilon i$ is the random error of city $i$.

In the geographically weighted regression model, since geospatial information is described by latitude and longitude coordinates, the distance is used as a calculation index with a small weight. Currently, there are three kinds of spatial weight functions, among which the most commonly used Gaussian weight function is as follows:

$$
W_{I}=\varnothing\left(d_{i} / \delta \theta\right)
$$

where $\varphi$ represents the standard normal density function; $\delta$ represents the standard deviation of the distance vector $d_{i}$. In calculating the distance weight, the attenuation effect needs to be considered, so usually an attenuation parameter is introduced, and the parameter $\theta$ is the attenuation parameter, or the bandwidth parameter.

\section{The Results of Spatial Characteristics of Manufacturing Production Space}

In the results of spatial characteristics of manufacturing production space, Section 4.1 is a partial qualitative description of the distribution characteristics of manufacturing production space at different scales, and Section 4.2 is a further in-depth study, which used four indicators to measure the spatial form characteristics and agglomeration characteristics of manufacturing production space patches (patches are the patches of manufacturing production space).

\subsection{The Multi-Scale Distribution of Manufacturing Production Space}

\subsubsection{Whole Domain}

Through 40 years of fast development after reform and opening up, the global city-region of the PRD has gradually entered a period of comprehensive transformation and development, and the manufacturing production space has gradually formed a unique distribution pattern. Currently, the total area of the manufacturing production space in the PRD is $1953.84 \mathrm{~km}^{2}$. From the overall distribution diagram (Figure 3), it can be seen intuitively that the manufacturing production space in the urban areas on both sides of the Pearl River estuary was the most densely distributed, and the development of concentrated contiguous forms have been formed. The situation of manufacturing production space in the periphery of the Pearl River Delta was relatively scattered, which was only clustered on a small scale along some traffic conditions with good or important location conditions, and which showed a "core-periphery" distribution pattern.

\subsubsection{City Scale}

The spatial distribution of manufacturing production space in different types of cities presented highly differentiated spatial characteristics, which were divided into three types: de-centralization type, uniformed contiguous type, and others.

De-centralized distribution: global cities (Guangzhou, Shenzhen), as was shown in Figure 5. The spatial distribution characteristics of manufacturing production space: the urban core area was obviously de-industrialized, but the core area retains a large number of urban-type manufacturing industries with an area smaller than one cell of $22.85 \mathrm{~m}^{2}$ (namely, $4.78 \mathrm{~m} \times 4.78 \mathrm{~m}$ ). In order to maintain the economic vitality of the urban core area and ease the pressure on employment, the core area of 
Guangzhou still retained a large number of urban-type manufacturing industries, and its production space was small (the area is less than one cell of $22.85 \mathrm{~m}^{2}$. There were 5738 POI of urban manufacturing enterprises, which accounted for $52 \%$ of the total number of manufacturing enterprises. Among them, Guangzhou was dominated by garment manufacturing enterprises with 2969, which accounted for 51\% of the total number of urban manufacturing enterprises and which was mainly concentrated in Haizhu District. Shenzhen's manufacturing was mainly small electronic information products manufacturing, such as microelectronics technology companies, digital technology companies, and intelligent electrical technology companies. Shenzhen's manufacturing production space was mainly concentrated in the north, especially in the northwest adjacent to Dongguan. The spatial distribution of manufacturing production space in the urban core area was a typical "empty cage for bird" mode.

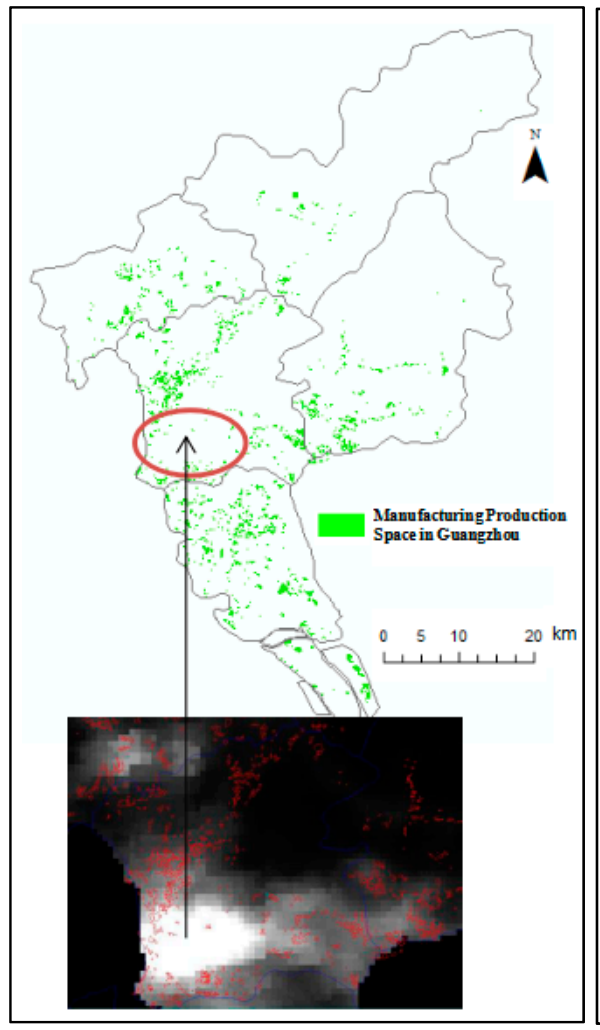

(a)

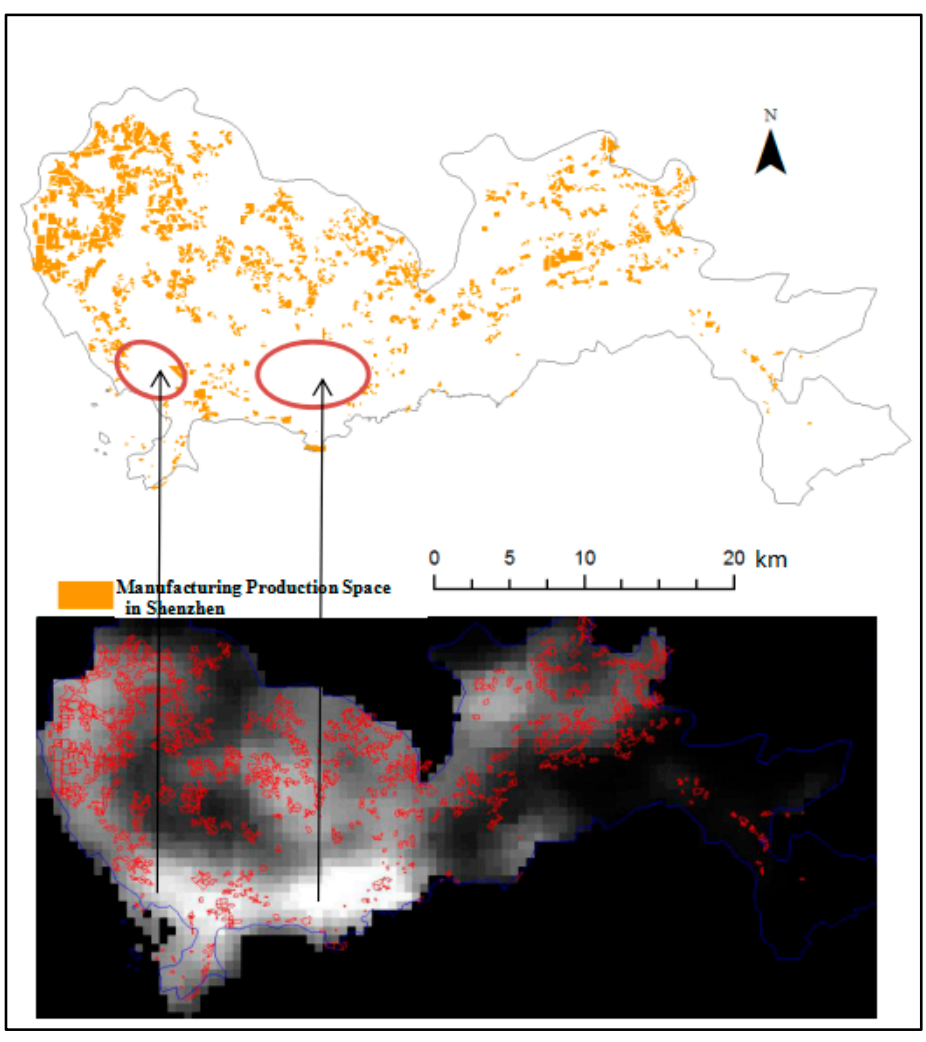

(b)

Figure 5. Guangzhou (a) and Shenzhen (b) manufacturing production space distribution diagram.

Uniformed continuous distribution: typical manufacturing cities (Foshan, Dongguan), as was shown in Figure 6. The spatial distribution characteristics of manufacturing production space: the development intensity (density index) of the manufacturing production space was high, and there was no obvious gathering center in the manufacturing production space, which was contiguous and evenly distributed.

Others: five other cities (Zhuhai, Jiangmen, Zhongshan, Huizhouand, Zhaoqing). The manufacturing production space of the other five cities had no obvious spatial distribution characteristics. 


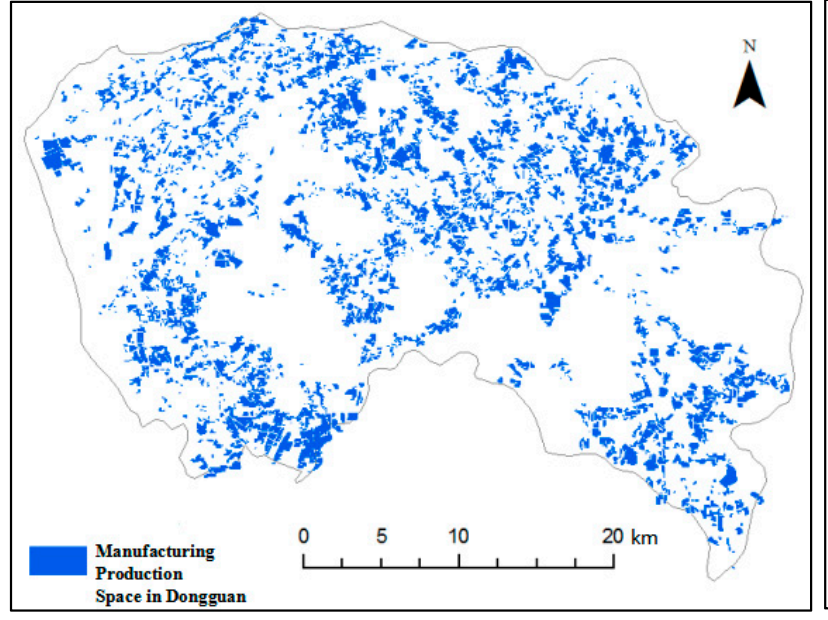

(a)

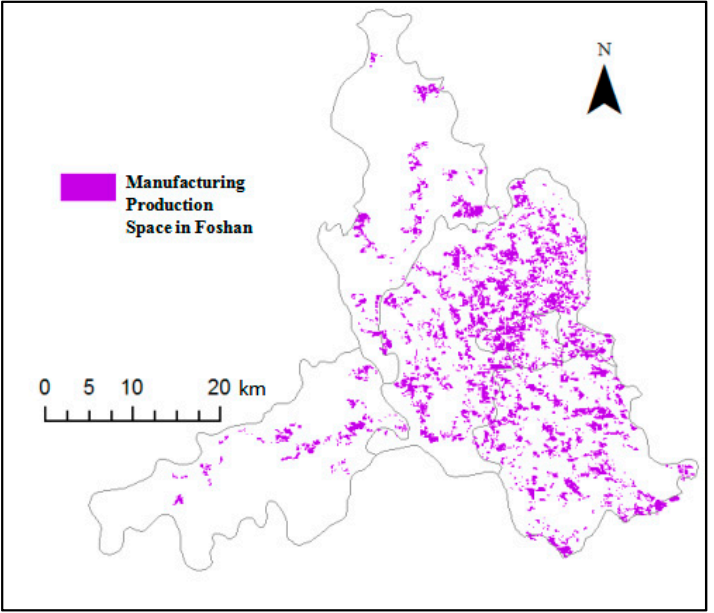

(b)

Figure 6. Distribution of manufacturing production space in (a) Dongguan and (b) Foshan.

\subsubsection{Typical Areas}

The urban space can be divided into production space, living space, and ecological space from the perspective of functional space [52]. Qualitative analysis of the distribution characteristics of manufacturing production space at a typical area scale revealed that the manufacturing production space in urban areas was intertwined with urban living space and ecological space. In accordance with the spatial relationship between the three, it could be divided into three distribution modes, as were shown in the sample graph of Figure 7. Therefore, it could be summarized into three typical spatial distribution patterns, as were shown in the schematic diagram of Figure 8.

The first type was the concentrated contiguous type (a): Shunde in Foshan and most areas in Dongguan, which have developed from the past professional town model.

The second type were uniformed interlaced type (b): they were distributed at the edge of the core city, which were adjacent to the residential area, ecological green space, etc., that were outside the city. They were mainly industrial parks, high-tech parks, etc.

The third type were scattered along the road type (c): distributed on the periphery of the PRD with large areas of ecological space, such as forests and farmland as the main body. The scale of manufacturing production space was small, which was along highways, national highways, and provincial highways. They were mainly small factories run by towns or villages.

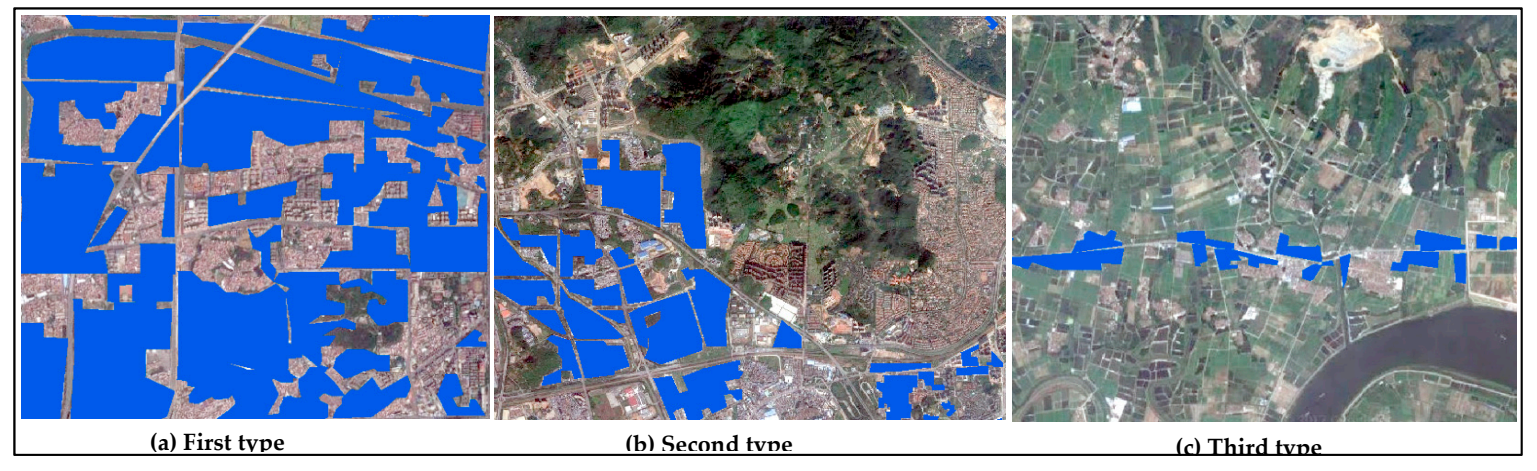

Figure 7. Sample graph. 


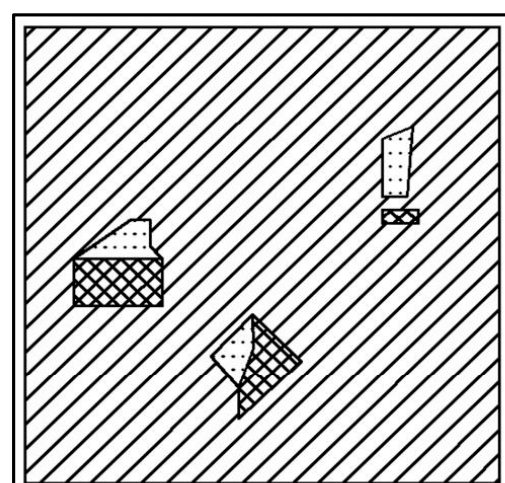

(a) First type

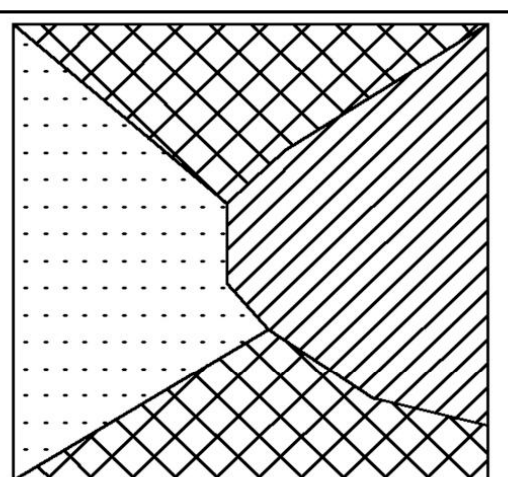

(b) Second type

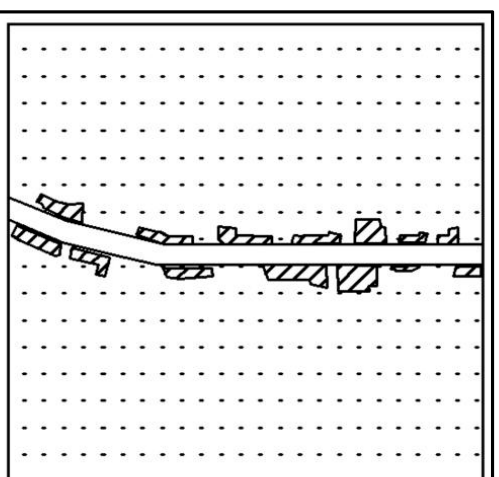

(c) Third type

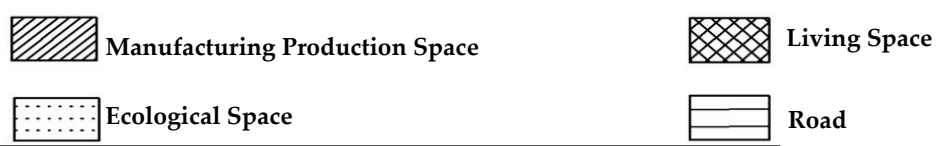

Figure 8. Mode pattern.

\subsection{Multi-scale Morphologies and Agglomerations of Manufacturing Production Space Patch}

Firstly, the method of kernel density estimation was used to measure the spatial agglomeration characteristics of patches in the whole region (Figure 9). Separately taking nine cities within the region as statistical units and taking 37 counties (districts) within the region as statistical units, the three indexes $(S K, C I, \rho)$ were constructed to further measure the spatial form characteristics of manufacturing production space patch at different scales.

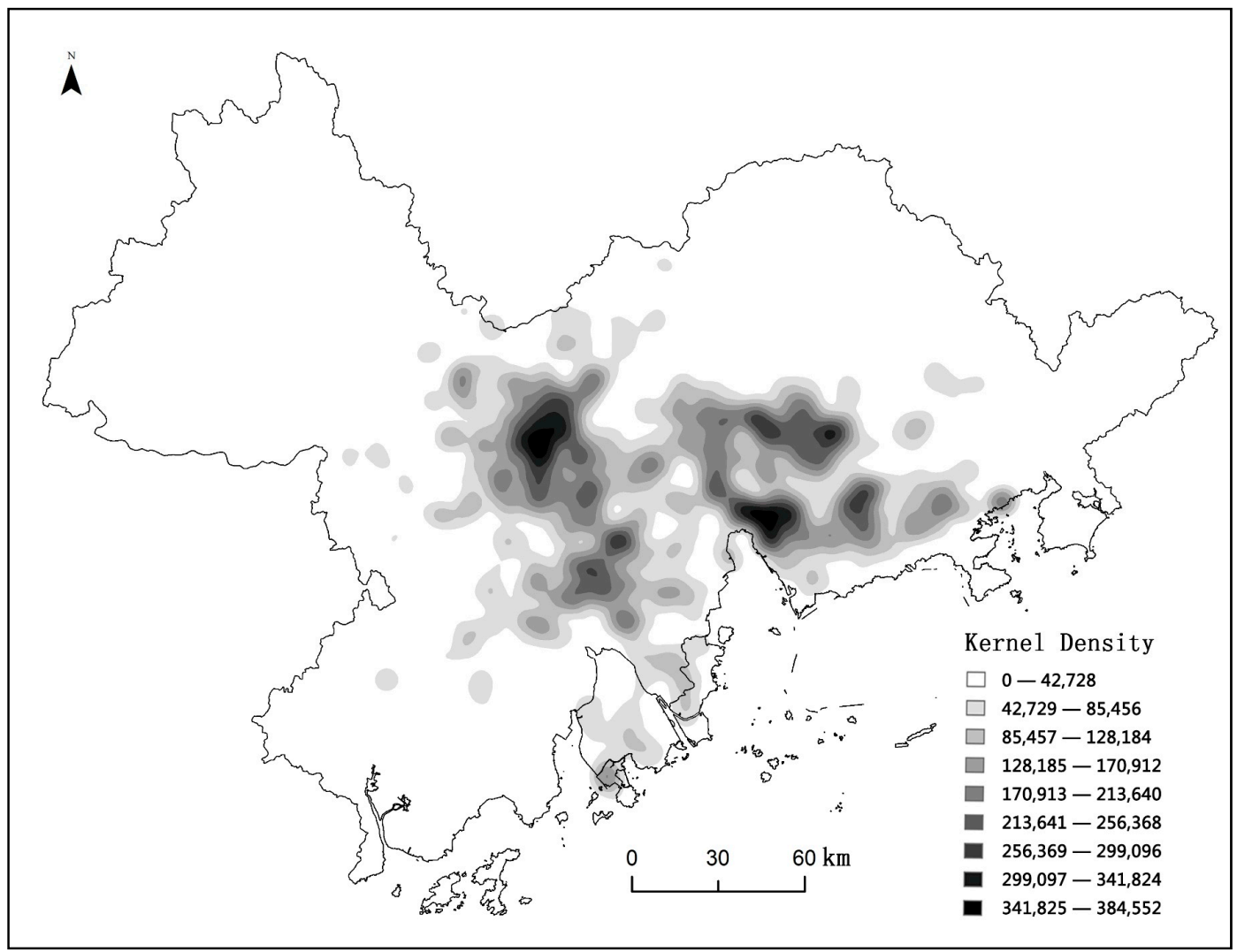

Figure 9. Density distribution map of the manufacturing production space patch. 


\subsubsection{Whole Domain}

As was shown in Figure 3, it could be seen intuitively that the manufacturing production space in the urban areas on both sides of the Pearl River estuary were the most densely distributed, furthermore, the kernel density distribution map of the manufacturing production space patch (Figure 9) indicated the characteristics of polycentric spatial agglomeration of manufacturing production space patch in the PRD. There were five agglomeration centers. Two major agglomeration centers: the first one was located in the middle of PRD (namely, Nanhai district), the second one was located on the east side of the Pearl River Estuary (namely, Baoan district and Changan town). Three secondary agglomeration centers were located in the Zhongshan city, the east of Dongguan city and the north of Shenzhen city. In addition, there were a large number of widely distributed small agglomeration centers, which were mainly distributed in the core area of the PRD, while there was nearly no agglomeration center in the periphery of the PRD.

\subsubsection{City-Level Analysis}

The scale of manufacturing production space in nine cities in the global city-region of the PRD was divided into three levels (Table 3). The first level was in orange: Foshan and Dongguan; the second level was in blue: Guangzhou, Shenzhen, Zhongshan, Jiangmen, and Huizhou; the third level was in green: Zhuhai and Zhaoqing. Among them, the combined manufacturing production space area of Foshan and Dongguan were close to half of the total area, which reached $46 \%$. Through the analysis of the development intensity (namely, $\rho$ ) of the manufacturing production space (Table 4), it was shown that the overall development intensity of the region was high $(26.84 \%)$, which was close to the international warning line of $30 \%$ (according to international practice, it is a warning line for a region to reach $30 \%$ of its land development intensity. Beyond this intensity, people's living environment will be affected) (http://www.tdzyw.com/). Through comparation of the development intensity of manufacturing production space between cities, it was found that the highest development intensity was $42.38 \%$ in Foshan, the lowest was $15.01 \%$ in Guangzhou, and the development intensity of cities such as Dongguan, Foshan, and Zhongshan, were all more than $30 \%$.

Table 3. Landscape indices of manufacturing production space of various cities in the PRD.

\begin{tabular}{ccccccccccc}
\hline Index & GZ & FS & DG & ZH & SZ & ZS & ZQ & JM & HZ & Total \\
\hline Number of patches & 1739 & 2186 & 2545 & 456 & 1212 & 1323 & 709 & 1530 & 1217 & 12,986 \\
$\begin{array}{c}\text { Perimeter of } \\
\text { patches/km }\end{array}$ & 2920.17 & 4728.64 & 4845.27 & 773.89 & 2322.17 & 2235.22 & 991.86 & 2169.84 & 1766.55 & $22,120.22$ \\
$\begin{array}{c}\text { Area of patches } / \mathrm{km}^{2} \\
\text { intensity index } \rho(\%)\end{array}$ & 215.05 & 467.91 & 417.69 & 76.87 & 202.66 & 182.43 & 79.26 & 169.66 & 137.98 & 1953.84 \\
\hline
\end{tabular}

Note: Patches are the patches of manufacturing production space.

Table 4. Fractal dimension, stability index and morphological compactness of manufacturing production space.

\begin{tabular}{cccccc}
\hline City & $\begin{array}{c}\text { Perimeter(P)-area(A)relational } \\
\text { Model }\end{array}$ & $\begin{array}{c}\text { Correlation } \\
\text { coefficient R }\end{array}$ & SK & CI & $\boldsymbol{\rho}(\mathbf{\%})$ \\
\hline GZ & $\ln \mathrm{A}=1.7467 \ln P-1.3500$ & 0.9418 & 0.3550 & 0.0050 & 15.01 \\
FS & $\ln \mathrm{A}=1.7316 \ln \mathrm{P}-1.2187$ & 0.9442 & 0.3450 & 0.0046 & 42.38 \\
DG & $\ln \mathrm{A}=1.7461 \ln \mathrm{P}-1.2919$ & 0.9351 & 0.3546 & 0.0044 & 33.36 \\
$\mathrm{ZH}$ & $\ln \mathrm{A}=1.8158 \ln \mathrm{P}-1.7154$ & 0.9574 & 0.3986 & 0.0113 & 24.02 \\
$\mathrm{SZ}$ & $\ln \mathrm{A}=1.7635 \ln \mathrm{P}-1.3439$ & 0.9317 & 0.3659 & 0.0061 & 25.05 \\
$\mathrm{ZS}$ & $\ln \mathrm{A}=1.7247 \ln \mathrm{P}-1.1716$ & 0.9474 & 0.3404 & 0.0060 & 36.76 \\
$\mathrm{ZQ}$ & $\ln \mathrm{A}=1.7445 \ln \mathrm{P}-1.3343$ & 0.9464 & 0.3535 & 0.0062 & 18.65 \\
$\mathrm{JM}$ & $\ln \mathrm{A}=1.7562 \ln \mathrm{P}-1.4239$ & 0.9476 & 0.3612 & 0.0060 & 24.45 \\
$\mathrm{HZ}$ & $\ln \mathrm{A}=1.728 \ln \mathrm{P}-1.1767$ & 0.9413 & 0.3426 & 0.0066 & 18.80 \\
\hline
\end{tabular}


The spatial morphological characteristics of the manufacturing production space in each city were shown in Table 4. On the whole, the distribution of manufacturing production space in nine cities was in a very balanced and stable state (namely, $S K$ ), and there was little difference between the nine cities. Through the analysis of the dispersion degree index (namely, $C I$ ) of the manufacturing production space of the nine cities, it was found that the degree of dispersion of the eight cities were high, and only Zhuhai was relatively concentrated.

In summary, the stability of manufacturing production space in nine cities was good, and the $S K$ value was not significantly different, while the compactness index (namely, CI) and the development intensity index (namely, $\rho$ ) were quite different. Therefore, in the next section (namely, Section 4.2.3), pushing down the scale and taking 37 counties (districts) in the region as statistical units, the compactness and development intensity of manufacturing production space in each county (district) were discussed in detail.

\subsubsection{County-Level Analysis}

The county (district) was used as a statistical unit to conduct an analysis of the degree of factor-gathering of manufacturing production space in the global city-region of the PRD. It could be seen from the compactness index (namely, CI) of Table 5 that there was a big difference in the degree of manufacturing production space of the counties (districts) in the global city-region of the PRD. The highest degree of dispersion was the manufacturing production space in Dongguan, which had compactness of 0.0044 . Relatively speaking, the manufacturing production space distribution of Fengkai County was the most concentrated with a compactness of 0.1160 . Further speaking, the four levels were divided by the average level of the entire PRD. The compactness of the first two types was relatively small, which was lower than the average value of each region; the latter two types were conversely. As was shown in Figure 10, in accordance with the distribution diagram of spatial visualization, in the counties (districts) in the core areas of the PRD, the distribution of manufacturing production space was relatively scattered in regions with strong influence from globalization; in the counties (districts) in the peripheral areas of the PRD, the industrialization process was relatively slow, which showed a state of agglomeration within the city. To sum up, the agglomeration pattern of the manufacturing space in the PRD industry presented a pattern of diffusion from the core to the periphery.

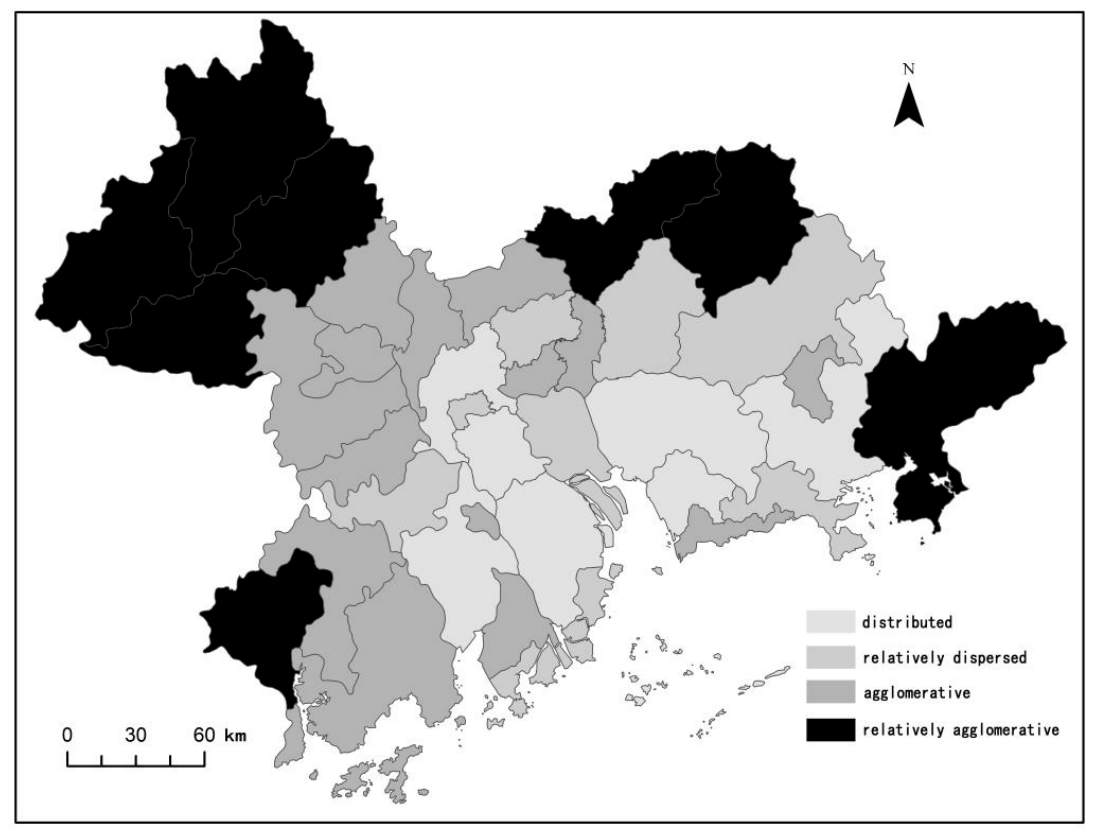

Figure 10. Compactness distribution of manufacturing production space in counties (districts) of the PRD. 
Table 5. Landscape indices of manufacturing production space in counties (districts) of the PRD.

\begin{tabular}{|c|c|c|c|c|}
\hline County/District/City & Number of Patches & Total Area of the Patch $\left(\mathrm{km}^{2}\right)$ & $C I$ & $\rho(\%)$ \\
\hline Guangzhou Core District & 215 & 14.97 & 0.0159 & 6.59 \\
\hline Baiyun District & 345 & 41.21 & 0.0117 & 17.32 \\
\hline Huangpu District & 122 & 26.69 & 0.0199 & 16.08 \\
\hline Panyu District & 483 & 92.56 & 0.011 & 28.31 \\
\hline Huadu District & 195 & 25.25 & 0.0156 & 11.43 \\
\hline Zengcheng District & 276 & 33.77 & 0.0128 & 18.45 \\
\hline Conghua District & 106 & 10.48 & 0.0217 & 13.27 \\
\hline Shenzhen Core District & 146 & 17.01 & 0.0198 & 7.95 \\
\hline Longgang district & 438 & 65.18 & 0.0109 & 24.14 \\
\hline Baoan District & 635 & 122.74 & 0.0091 & 33.26 \\
\hline Zhuhai Core District & 295 & 55.37 & 0.0142 & 23.26 \\
\hline Doumen District & 152 & 20.95 & 0.0198 & 19.95 \\
\hline Foshan Core District & 229 & 49.81 & 0.0142 & 45.70 \\
\hline Shunde District & 634 & 132.94 & 0.0092 & 44.31 \\
\hline Nanhai District & 974 & 208.6 & 0.0068 & 45.85 \\
\hline Sanshui City & 218 & 48.75 & 0.0151 & 36.11 \\
\hline Gaoming District & 142 & 31.98 & 0.0184 & 33.31 \\
\hline Jiangmen Core District & 178 & 18.28 & 0.0177 & 26.11 \\
\hline Taishan City & 188 & 18.28 & 0.0177 & 10.04 \\
\hline Xinhui City & 660 & 75.6 & 0.0091 & 38.77 \\
\hline Kaiping City & 220 & 23.57 & 0.0168 & 18.71 \\
\hline Heshan City & 275 & 27.62 & 0.0147 & 65.76 \\
\hline Enping City & 53 & 11.38 & 0.0372 & 13.39 \\
\hline Zhaoqing Core District & 154 & 15.13 & 0.0184 & 29.10 \\
\hline Guangning County & 50 & 3.68 & 0.0347 & 11.87 \\
\hline Huaiji County & 46 & 2.59 & 0.0356 & 3.92 \\
\hline Fengkai County & 4 & 0.15 & 0.1160 & 0.41 \\
\hline Deqing County & 39 & 3.73 & 0.0370 & 9.33 \\
\hline Gaoyao City & 210 & 26.05 & 0.0172 & 23.47 \\
\hline Sihui City & 167 & 21.48 & 0.0183 & 24.41 \\
\hline Huizhou Core District & 145 & 14.87 & 0.0191 & 14.44 \\
\hline Boluo County & 360 & 37.14 & 0.0118 & 23.51 \\
\hline Huidong County & 117 & 8.47 & 0.0216 & 6.67 \\
\hline Longmen County & 24 & 2.59 & 0.0572 & 7.19 \\
\hline Huiyang City & 571 & 70.67 & 0.0100 & 6.93 \\
\hline Dongguan City & 2545 & 417.69 & 0.0044 & 32.91 \\
\hline Zhongshan City & 1323 & 182.43 & 0.0062 & 36.27 \\
\hline
\end{tabular}

Note: Patches are the patches of manufacturing production space.

According to the development intensity of manufacturing production space, Heshan City had the highest development intensity (65.67\%). All the districts under the jurisdiction of Foshan City (Foshan Core District, Shunde District, Nanhai District, Sanshui City, Gaoming District), Baoan District, Dongguan City and Zhongshan City had more than 30\% development intensity. The development intensity of the core areas of the global cities, such as Guangzhou Core District and Shenzhen Core District, were relatively small.

\section{The Results of GWR Model}

\subsection{Geographically Weighted Regression Analysis Results}

\subsubsection{Overall Region}

The important reference indicators of the geographically weighted regression model are shown in Table 6 below. Through eliminating the low correlation and collinear independent variables, there were five main explanatory variables left, such as the urbanization rate, fixed assets investment, 
FDI enterprises, gross industrial production, and the employment population. The degree of fitting of the model $\mathrm{R}$ was 0.78 , the correction fit R2Adjusted was 0.75 , and the fitting effect was good.

Table 6. Model estimation results.

\begin{tabular}{cccc}
\hline OID & VARNVME & VARIABLE & DEFINITION \\
\hline 0 & Bandwidth & 480298.9314 & \\
1 & ResidualSquares & 47899.64803 & \\
2 & EffectiveNumber & 6.436530842 & \\
3 & Sigma & 39.58811627 & \\
4 & AICc & 388.719898 & \\
5 & R2 & 0.783257524 & Frixed Assets Investment \\
6 & R2Adjusted & 0.744704074 & Manufacturing Production Space $\left(\right.$ area $\left./ \mathrm{km}^{2}\right)$ \\
7 & Dependent Field & 0 & Gross Industrial Product \\
8 & Explanatory Field & 1 & The Employment Population \\
9 & Explanatory Field & 2 & \\
10 & Explanatory Field & 3 & \\
11 & Explanatory Field & 4 & 5 \\
12 & Explanatory Field & 5 &
\end{tabular}

\subsubsection{Each Counties (Districts)}

As was shown in Figure 11a, except that the residual of Foshan core district exceeded 2.5 times the standard deviation, the fitting effect of the model was general, and 36 other counties and districts had achieved better fitting effect. Standardized residuals of more than half of the counties (districts) models were controlled within a range of less than 0.5 times. As was shown in Figure 11b, the distribution of the degree of fitting of the local regression model was characterized by a stepwise rise from the west to the east.

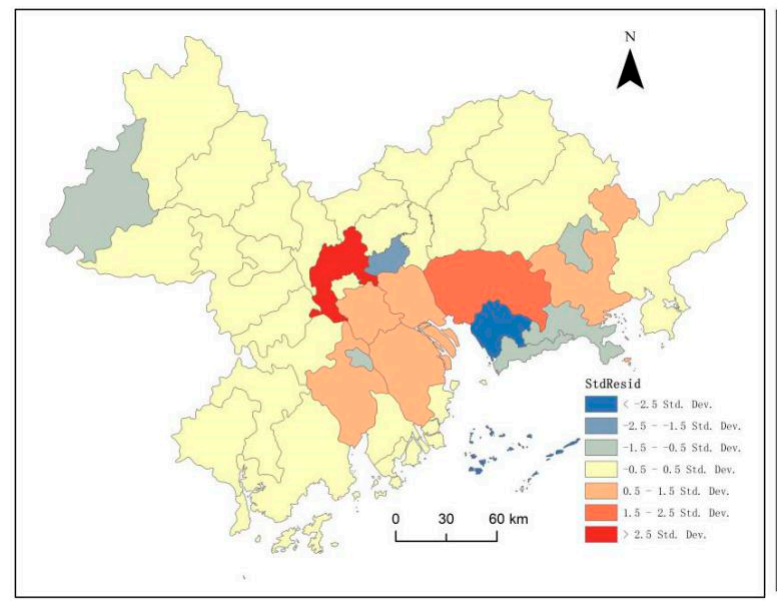

(a)

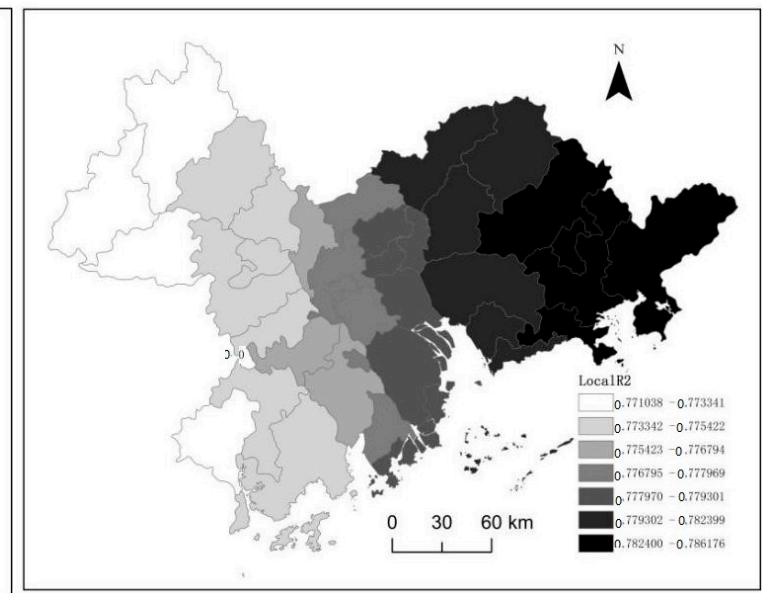

(b)

Figure 11. (a) Distribution of standardized residuals; (b) Distribution of degree of fitting.

\subsection{Spatial Heterogeneity of Influencing Factors}

The spatial visualization distribution of the regression parameters of five main explanatory variables, such as urbanization rate (Figure 12a), fixed asset investment (Figure 12b), number of FDI firms (Figure 12c), gross industrial production (Figure 12d), and the employment population (Figure 12e) were shown in Figure 12. 

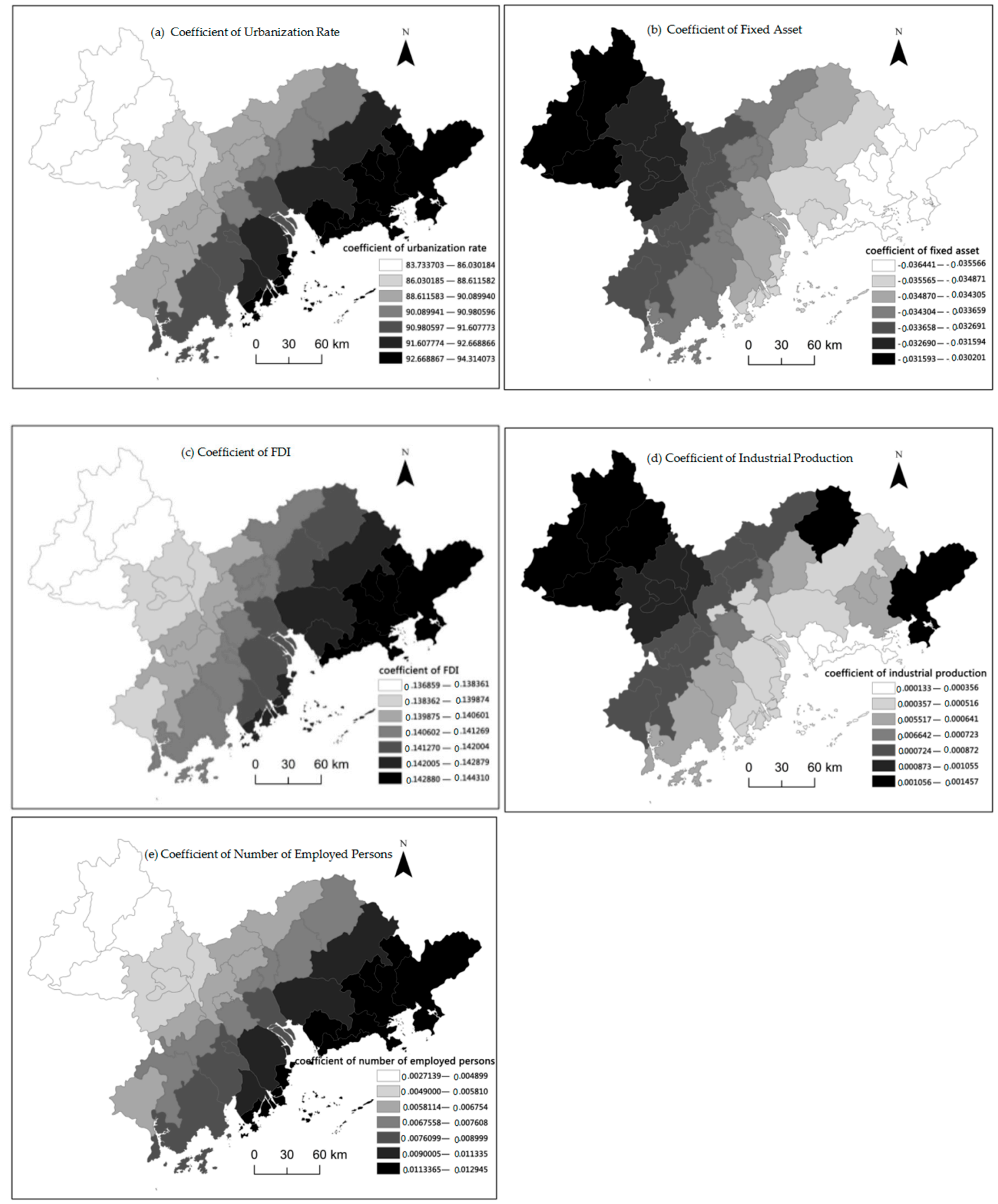

Figure 12. Distribution of coefficients of five explanatory variables in counties (districts).

\subsubsection{Spatial Variability of Urbanization Has an Impact on Manufacturing Production Space}

In the past forty years since the reform and opening up, the urbanization process of the PRD and the development of manufacturing production space have changed and influenced each other [72,75]. As a destination for manufacturing investment in developed countries, the evolution of the regional economic structure in the global city-region of the PRD was different. As the destination to undertake the manufacturing investment of the developed countries, the evolution of the economic structure of these developing countries was different from that of the post-industrialized countries from the agriculture to the manufacturing industry to the service industry, but the parallel development of the manufacturing industry and the service industry. Therefore, from the overall region to the 
prefecture-level cities to counties (districts) as well as other different scales, the two development models of the industrialization and the deindustrialization were being conducted at the same time. From the regression parameters of the urbanization rate of Figure 12a, it could be found that even if the urbanization rate was extremely high, such as the core area of Shenzhen, or the county with medium urbanization rate, such as Longmen County, both of which were positively correlated with the manufacturing production space and the impacts were great. The four counties of Zhaoqing City (Guangning County, Huaiji County, Fengkai County, and Deqing County) with the lowest urbanization rate had less influence on the development of manufacturing production space.

\subsubsection{Spatial Variability of the Impact of Fixed Asset Investment on Manufacturing Production Space}

From the perspective of the regression coefficient of fixed asset investment (Figure 12b), the government's fixed asset investment projects were negatively correlated with the development of manufacturing production space. The peripheral counties (districts) of the PRD, especially some counties (districts) in Zhaoqing, were influenced by the government fixed asset investment. The negative impact of capital investment on the manufacturing industry was the most significant, which was greatly related to the management of some regional governments, the fact that some of the results of the project were unfortunate, and waste of resources.

\subsubsection{Spatial Variability of the Influence of Outward Dynamics on Manufacturing Production Space}

From the regression parameters of the number of FDI enterprises (Figure 12c), it could be known that the economic globalization had a positive effect on the manufacturing production space and that there was regional imbalance in this promotion. The contribution of FDI enterprises gradually decreased from southeast to northwest. As an active region of economic globalization, the southeastern part of the PRD was closer to Hong Kong and Macau and its manufacturing industry had more obvious advantages.

\subsubsection{Spatial Variability of Industrialization Impact on Manufacturing Production Space}

It could be seen from the regression parameters of the regional industrial production value (Figure 12d) that the industrialization process had a positive effect on the manufacturing production space, but there was a regional imbalance in this promotion. The core areas of the global city-region of the PRD, on both sides of the Pearl River estuary, especially the east coast counties (districts), had basically entered the post-industrial period [60]. The development of manufacturing production space was less influenced by industrialization, while in the peripheral areas of the PRD, most counties (districts) were still in the middle stage of industrialization development [60] and the development of manufacturing production space was greatly influenced by the regional industrialization.

\subsubsection{Spatial Variability of Employment Population's Influence on Manufacturing Production Space}

Judging from the regression coefficient of employment population (Figure 12e), the employment population had a negative effect on the development of manufacturing production space. This conclusion was contrary to the conclusion that traditional labor force, as an important factor of neoclassical economic growth, played a positive role in promoting regional industrial development. From the current stage of development of the global city-region of the PRD, with the rise of labor costs, more and more manufacturing industries were beginning to transform into high technology, automation and intelligence, and labor-intensive manufacturing enterprises were increasingly transforming into technology-intensive development, so the role of the labor factor became smaller and smaller, which presented a weak negative correlation now. Moreover, this correlation had regional imbalances, "from west to east", showing a pattern of increasing negative direction. After the financial crisis in 2008, the industrial upgrading of the PRD accelerated and the eastern region has gradually upgraded into a science and technology innovation corridor. The regional service industry has been growing rapidly and gathering a large number of employed people. The manufacturing industry was developing 
towards high-tech intelligence, and its development was becoming less and less dependent on the demographic dividend.

\section{Discussion}

\subsection{Comparison of Spatial Distribution Characteristics between Developing Countries and Western Countries}

The manufacturing production space in western countries would be largely distributed in the core cities at the beginning, then transferred to peripheral areas [76], and further transferred to developing countries [77]. At present, the vast majority of western countries' global city-regions have gone through deindustrialization. The leading industrial space in the region is mainly producer services and knowledge-intensive industries. Only a few western countries (such as Germany) still have a small number of specialized high-tech manufacturing industries in their global city-regions [78]. According to this article, after a period of economic globalization, the spatial pattern of manufacturing production space in global city-regions in developing countries was significantly different from that in western countries. There was no large amount of manufacturing production space in core cities (such as Guangzhou and Shenzhen). It was mainly distributed in peripheral areas of core cities (Figure 5), typical manufacturing cities (Figure 6) and peripheral villages and towns (Figure 3), and presented a multi-center distribution pattern of core-periphery (Figure 9). In addition, three typical distribution patterns were summarized in this study (Figure 8). The first model was mainly distributed in typical manufacturing cities. Some development zones have extensive land use and low utilization efficiency. The second kind was mainly distributed in the periphery of global cities. The existence of some enterprises with high pollution, high energy consumption, and high emission affects the living environment and sustainable development of cities to a certain extent. For this kind of distribution pattern, the proportion and spatial distribution relationship among production, life and ecology should be well coordinated. The third distribution mode was mainly distributed in the villages and towns around the region. Due to the weak intensity and breadth of planning control, the occupation of agricultural land and forest land is very common, so we should pay attention to accurate planning in the future.

\subsection{Optimal Control of Spatial Morphological Characteristics}

The manufacturing production space in global city-region of PRD had good stability (Table 4), and was generally in the mature stage of industrialization [79]. However, its compactness had strong spatial and temporal heterogeneity (Figure 11), and the development intensity (Table 5) in some areas was too high. In 2006, the compactness of the counties (districts) in the PRD was 0.0299 [60], while the average value of the 37 counties (districts) in this study had reached 0.0207, with the highest value reaching 0.1160 . Therefore, from 2006 to 2017, the overall compactness of the manufacturing production space in the PRD has been greatly improved. However, in the early and middle stages of industrialization, gross industrial output value's level was relatively low [72], so its manufacturing production space was less intensive. According to the results of this study, with the development of economic globalization and industrialization, the manufacturing production space in the PRD was generally more intensive in the mature period of industrialization due to the increase in the compactness of the manufacturing production space form and the increase in the output value of manufacturing production space per unit area, and was gradually getting rid of the development mode of relying on extensive utilization of manufacturing production space.

However, in a few areas, such as Heshan City, the development intensity of manufacturing production space was very high (Table 5), while gross industrial output value is relatively low, and the extensive use of manufacturing production space was very serious. For this type of counties (districts), we should pay attention to revitalizing the stock space and promoting the change from incremental expansion to inventory revitalization. In other areas, such as Foshan, Dongguan and Zhongshan, the output value of manufacturing production space per unit area was very high, but the development 
intensity of manufacturing production space exceeded $30 \%$ (Table 4 , Table 5), which was not conducive to the sustainable development of the city. Attention should be paid to control the development intensity in the future.

\subsection{A Comparison of Driving Factors between Developing Countries and Western Countries}

The new international division of labor had not yet begun in the middle of the 20th century. The industrial system in the world cities and their surrounding areas was complete and there was a large amount of manufacturing production space [80]. With the development of new international division of labor, global manufacturing activities began to gather in the PRD. As transportation and information technology have further promoted the space-time compression of geographic space, the multi-center spatial node of the PRD global city-region has gathered manufacturing production space with close industrial ties [81], becoming a post-Ford regional production platform with global market competitiveness [5,6]. Therefore, from the perspective of evolutionary economic geography, under the new round of global capital circulation, manufacturing production space patterns in global city-regions of developing countries was a scaled-up version of manufacturing production space pattern in world cities of western countries before the new international division of labor, but the driving factors for the formation of the two were similar and different.

In the rapid development stage of industrialization, whether in western countries [82] or developing countries (Figure 12), the formation of manufacturing production space was strongly related to the development of urbanization (i.e., urbanization rate, Figure 12a) and industrialization in the region, especially the level of infrastructure such as transportation (i.e., investment in fixed assets, Figure $12 b$ ), the level of industrialization (i.e., regional industrial production value, Figure 12d), and other factors had a positive role in promoting. The differences were shown as follows. Before the new international division of labor was launched, the formation of manufacturing production space in western countries' world cities and their surrounding regions was mainly driven by domestic internal capital, and the contacts of manufacturing enterprises were mainly limited to regional internal contacts [80]. At present, the driving factors for the spatial distribution of manufacturing production space in developing countries include not only domestic capital but also a large amount of foreign capital (i.e., the number of FDI enterprises, Figure 12c) and the close connection with other global city-regions in the world with transnational manufacturing enterprises as the carrier.

\section{Conclusions}

This study mainly figured out the spatial characteristics of manufacturing production space at different scales, and influencing factors of the spatial pattern of manufacturing production space in the global city-regions of developing countries. Then, it compared the similarities and differences of spatial characteristics of manufacturing production space and its influencing factors in the global city-regions between developing countries and western countries, and put forward some policy suggestions for the optimal control and precise planning of manufacturing production space.

According to this article, after a period of economic globalization, the spatial pattern of manufacturing production space in global city-regions in developing countries was significantly different from that in western countries. In the new round of global capital cycle, manufacturing production space was mainly distributed in the global city-regions of developing countries. Due to the further promotion of space-time compression of traffic and communication technology, different from the 1950s, the manufacturing production space in western countries was mainly distributed in the core cities, and the manufacturing production space was mainly distributed in the secondary cities of the global city-region (namely, typical manufacturing cities). While in different historical periods and in different regions, the factors that affect the spatial distribution of manufacturing production space in the urban-regions of the developing countries and the western countries have similarities, which are related to the level of local urbanization, the level of industrialization, the level of government investment in the infrastructure, and so on. Further speaking, the current global city-regions of 
developing countries are still in the process of rapid industrialization, and the export-oriented impetus of economic globalization plays an important role in regional development. Therefore, the optimal regulation and control of manufacturing production space and future development planning in global city-regions of developing countries (which maybe have much bigger area compared with western countries' global city-regions) in the current period cannot copy the western experience. Then, based on the local development background and the past development experience of western countries used for reference, the study made further efforts to provide the policy references of intensive regulation and control policies of manufacturing production space according to the agglomeration characteristics of manufacturing production space under different spatial scales.

In order to guide local industrial policy and urban spatial planning precisely and appropriately, in this study manufacturing production space based on RS technology and POI data extraction is more precise and continuous. It can enrich the practical content applied to developing countries, and the analysis results of multi-scale, continuous, and accurate spatial characteristics of manufacturing production space have important implications for China's policymakers. It is also essential for local governments in global city-region of PRD and other similar global city-regions of developing countries to recognize that under different scales the distribution characteristics of manufacturing production space and the agglomeration characteristics of spatial form are different. It is not simply extensive agglomeration or diffusion that can accurately explain its diversified spatial characteristics. The specific main policy recommendations are as follows:

(1) For the local industrial space optimization control, cannot simply extensive promotion or containment. On the basis of ensuring the overall industrial ecological balance in the region, the local governments should make precise regulation according to the actual situation of the development of manufacturing production space in different cities.

(2) For the core districts in global cities, we should continue to control the distribution of manufacturing production space and promote APS distribution with higher industrial added value and control function. For the peripheral areas of global cities, the local government should control the distribution of manufacturing enterprises of "three highs" _ _high pollution, high energy consumption, and high emission.

(3) For typical manufacturing cities, the districts with development intensity of more than $30 \%$ should be strictly controlled and the stock of extensive utilization of manufacturing production space should be actively activated.

(4) The agglomeration degree of manufacturing production space in the peripheral counties (districts) of the PRD is better, but the output value of regional manufacturing industry is relatively backward. Therefore, the local government should control the development intensity of manufacturing production space, and more importantly, improve the technological content of manufacturing enterprises and promote innovation and development.

Author Contributions: Conceptualization, D.X. and B.L.; materials acquisition and analysis, B.L.; data interpretation, B.L.; writing—original draft preparation, B.L.; writing—review and editing, Y.T.

Funding: This research was funded by the National Natural Science Foundation of China, grant number 41930646 and 41801157; the Guangdong Provincial Laboratory sub project, grant number 99147-42080011.

Acknowledgments: The authors would like to express their gratitude to Associate Professor Yang Ren, for his attentive reading and valuable suggestions for revision. The authors also thank Sun Shenlong for technical assistance of the research.

Conflicts of Interest: The authors declare no conflict of interest. 


\section{References}

1. Thierstein, A.; Lüthi, S.; Kruse, C.; Gabi, S.; Glanzmann, L. Changing value chain of the Swiss knowledge economy: Spatial impact of intra-firm and inter-firm networks within the emerging Mega-City Region of Northern Switzerland. Reg. Stud. 2008, 42, 1113-1131. [CrossRef]

2. Jacobs, W.; Rietbergen, T.; Atzema, O.; Grunsven, L.; Dongen, F. The Impact of Multinational Enterprises (MNEs) on Knowledge-Intensive Business Services (KIBS) Start-ups: Empirical Evidence from the Dutch Randstad. Reg. Stud. 2016, 50, 728-743. [CrossRef]

3. Simmie, J. Knowledge spillovers and reasons for the concentration of innovative SMEs. Urban. Stud. 2002, 39, 885-902. [CrossRef]

4. Romijn, H.; Albu, M. Innovation, networking and proximity: Lessons from small high technology firms in the UK. Reg. Stud. 2002, 36, 81-86. [CrossRef]

5. Scott, A.J. Global City-Regions: Trends, Theory, Policy; Oxford University Press: Oxford, UK, 2001.

6. Scott, A.J. Globalization and the Rise of City-Regions. Eur. Plan. Stud. 2001, 9, 813-826. [CrossRef]

7. Daniels, P.W. Book review: Global city regions: Their emerging forms. Prog. Hum. Geog. 2002, 26, 714-715. [CrossRef]

8. Romero, V.; Solís, E.; De Ureña, J.M. Beyond the metropolis: New employment centers and historic administrative cities in the Madrid global city region. Urban. Geogr. 2014, 35, 889-915. [CrossRef]

9. Pain, K. Examining 'core-periphery' relationships in a global city-region: The case of London and South East England. Reg. Stud. 2008, 42, 1161-1172. [CrossRef]

10. Varis, M.; Tohmo, T.; Littunen, H. Arriving at the Dawn of the New Economy: Is Knowledge-Based Industrial Renewal Possible in a Peripheral Region? Eur. Plan. Stud. 2014, 22, 101-125. [CrossRef]

11. Rodriguez-Pose, A.; Fitjar, R.D. Buzz, Archipelago Economies and the Future of Intermediate and Peripheral Areas in a Spiky World. Eur. Plan. Stud. 2013, 21, 355-372. [CrossRef]

12. Lin, G.C.S. Toward a post-socialist city? Economic tertiarization and urban transformation in the Guangzhou metropolis, China. Eurasian Geogr. Econ. 2004, 45, 18-44. [CrossRef]

13. Daniels, P.W.; Ho, K.C.; Hutton, T. Service industries and Asia-Pacific cities: Introduction and overview. In Service Industries and Asia-Pacific Cities: New Development Trajectories; Routledge: London, UK, 2005; pp. 1-18.

14. Zhao, M.; Derudder, B.; Huang, J. Examining the transition processes in the Pearl River Delta polycentric mega-city region through the lens of corporate networks. Cities 2017, 60, 147-155. [CrossRef]

15. Wei, Y.D. Restructuring for growth in urban China: Transitional institutions, urban development, and spatial transformation. Habitat Int. 2012, 36, 396-405. [CrossRef]

16. Bie, J.B.; Jong, M.; Derudder, B. Greater Pearl River Delta: Historical Evolution towards a Global City-Region. J. Urban. Technol. 2015, 22, 103-123. [CrossRef]

17. Ye, Y.Y.; Wu, K.M.; Xie, Y.C.; Huang, G.Z.; Wang, C.J.; Chen, J. How firm heterogeneity affects foreign direct investment location choice: Micro-evidence from new foreign manufacturing firms in the Pearl River Delta. Appl. Geogr. 2019, 106, 11-21. [CrossRef]

18. Yeh, A.G.; Yang, F.F.; Wang, J. Producer service linkages and city connectivity in the mega- city region of China: A case study of the Pearl River Delta. Urban. Stud. 2015, 52, 2458-2482. [CrossRef]

19. Zhang, X.; Kloosterman, R.C. Connecting the 'Workshop of the World': Intra-and Extra-Service Networks of the Pearl River Delta City-Region. Reg. Stud. 2016, 50, 1069-1081. [CrossRef]

20. Zhao, S.X.B.; Zhang, L. Foreign direct investment and the formation of global city-regions in China. Reg. Stud. 2007, 41, 979-994. [CrossRef]

21. Brouwer, A.E.; Mariotti, I.; van Ommeren, J.N. The firm relocation decision: An empirical investigation. Ann. Reg. Sci. 2004, 38, 335-347. [CrossRef]

22. Scott, A.J. Locational patterns and dynamics of industrial activity in the modern metropolis. Urban. Stud. 1982, 19, 111-142. [CrossRef]

23. Scott, A.J. Industrial organization and the logic of intra-metropolitan location: I. Theoretical considerations. Econ. Geogr. 1983, 59, 233-250. [CrossRef]

24. Arauzo-Carod, J.-M.; Viladecans-Marsal, E. Industrial location at the intra-metropolitan level: The role of agglomeration economies. Reg. Stud. 2009, 43, 545-558. [CrossRef] 
25. Scott, A.J. Industrial organization and the local of intra-metropolitan location, III: A case study of the women's dress industry in the Greater Los Angeles Region. Econ. Geogr. 1984, 60, 3-27. [CrossRef]

26. Dicken, P. Global Shift: Reshaping the Global Economic Map in the 21st Century; Sage: Thousand Oaks, CA, USA, 2003.

27. Broadman, H.; Sun, X. The Distribution of Foreign Direct Investment in China. World Econ. 1997, 20, 339-361. [CrossRef]

28. Zhu, S.J.; He, C.F. Global, regional and local: New firm formation and spatial restructuring in China's apparel industry. GEO J. 2014, 79, 237-253. [CrossRef]

29. Zhou, R.B.; Li, X.W. Evolution of spatial pattern and influencing factors of manufacturing industries in Guangdong Province. Hum. Geogr. 2017, 32, 95-102.

30. He, C.F.; Dennis Wei, Y.H.; Pan, F.H. Geographical concentration of manufacturing industries in China: The importance of spatial and industrial scales. Eurasian Geogr. Econ. 2007, 48, 603-625. [CrossRef]

31. Gao, B.Y.; Liu, W.D.; Michael, D. State land policy, land markets and geographies of manufacturing: The case of Beijing, China. Land Use Policy 2014, 36, 1-12.

32. Zhang, X.; Huang, P.; Sun, L.; Wang, Z.H. Spatial evolution and locational determinants of high-tech industries in Beijing. Chin. Geogr. Sci. 2013, 23, 249-261. [CrossRef]

33. Halbert, L.; Rouanet, H. Filtering Risk Away: Global Finance Capital, Transcalar Territorial Networks and the (Un) Making of City-Regions: An Analysis of Business Property Development in Bangalore, India. Reg. Stud. 2014, 48, 471-484. [CrossRef]

34. Wei, Y.D.; Bi, X.J.; Wang, M.F.; Ning, Y.M. Globalization, economic restructuring, and locational trajectories of software firms in Shanghai. Prof. Geogr. 2016, 68, 211-226. [CrossRef]

35. Yeh, A.G.; Li, X. An integrated remote sensing and GIS approach in the monitoring and evaluation of rapid urban growth for sustainable development in the Pearl River Delta, China. Int. Plan. Stud. 1997, 2, 193-210. [CrossRef]

36. Gong, J.Z.; Liu, Y.S.; Xia, B.C. Spatial heterogeneity of urban land-cover landscape in Guangzhou from 1990 to 2005. J. Geogr. Sci. 2009, 19, 213-224. [CrossRef]

37. Kuang, W.H. Spatio- temporal patterns of intra- urban land use change in Beijing, China between 1984 and 2008. Chin. Geogr. Sci. 2012, 22, 210-220. [CrossRef]

38. Wang, Y.F.; Liu, Y.S.; Li, Y.H.; Li, T.T. The spatio-temporal patterns of urban-rural development transformation in China since 1990. Habitat Int. 2016, 53, 178-187. [CrossRef]

39. Liu, X.P.; Hu, G.H.; Chen, Y.M.; Li, X.; Xua, X.C.; Li, S.Y.; Pei, F.S.; Wang, S.J. High-resolution multi-temporal mapping of global urban land using Landsat images based on the Google Earth Engine Platform. Remote Sens. Environ. 2018, 209, 227-239. [CrossRef]

40. Ding, J.; Wang, K.Y. Spatial pattern and morphological characteristics of industrial production space and influential factors in the Pearl River Delta urban agglomeration. Prog. Geogr. 2016, 35, 610-621. (In Chinese)

41. Zhang, L.L.; Yue, W.Z.; Liu, Y.; Fan, P.L.; Wei, Y.H. Suburban industrial land development in transitional China: Spatial restructuring and determinants. Cities 2018, 78, 96-107. [CrossRef]

42. Ding, J.; Wang, K.Y. Spatio-temporal evolution of industrial production space and its driving mechanisms in Pearl River Delta urban agglomeration. Geogr. Res. 2018, 37, 53-66. (In Chinese)

43. Wang, N.C.; Liu, Y.F.; Wang, J.Z.; Qian, X.J.; Zhao, X.Z.; Wu, J.P.; Wu, B.; Yao, S.J.; Fang, L. Investigating the Potential of Using POI and Nighttime Light Data to Map Urban Road Safety at the Micro-Level: A Case in Shanghai, China. Sustainability 2019, 11, 4739. [CrossRef]

44. Min, Y.; Tinghua, A.I.; Wei, L.U.; Cheng, X.; Qi, Z. A real-time generalization and multi-scale visualization method for poi data in volunteered geographic information. Acta Geod. Cartogr. Sin. 2015, 44, 228-234.

45. Chen, W.; Liu, L.; Liang, Y. Retail center recognition and spatial aggregating feature analysis of retail formats in guangzhou based on poi data. Geogr. Res. 2016, 35, 703-716.

46. Hu, Y.F.; Han, Y.Q. Identification of Urban Functional Areas Based on POI Data: A Case Study of the Guangzhou Economic and Technological Development Zone. Sustainability 2019, 11, 1385. [CrossRef]

47. Wang, J.C. Modern Industrial Geography; China Science and Technology Press: Beijing, China, 1994. (In Chinese)

48. Lin, G.C.S. Red Capitalism in South. China: Growth and Development of the Pearl River Delta; University of British Columbia Press: Vancouver, BC, Canada, 1997; pp. 1-219.

49. Sit, V.F.S.; Yang, C. Foreign-investment-induced Exo-urbanisation in the Pearl River Delta, China. Urban Stud. 1997, 34, 647-677. [CrossRef] 
50. Liu, Y.; Liang, Y.; Ma, S.; Huang, K.; Liu, Y.; Liang, Y.; Ma, S.; Huang, K. Divergent developmental trajectories and strategic coupling in the pearl river delta: Where is a sustainable way of regional economic growth? Sustainability 2017, 9, 1782. [CrossRef]

51. Wei, Y.D.; Ye, X.Y. Urbanization, urban land expansion and environmental change in China. Stoch. Envrion. Res. Risk Assess. 2014, 28, 757-765. [CrossRef]

52. Li, G.D.; Fang, C.L. Quantitative function identification and analysis of urban ecological-production-living spaces. Acta Geogr. Sinica 2016, 71, 49-65.

53. Yang, C. Cross-boundary integration of the Pearl River Delta and Hong Kong-An emerging global city-region in China. In Globalization and the Chinese City; Wu, F.L., Ed.; Routledge Press: London, UK, 2006; pp. 125-147.

54. Guangdong Burenu of Statistics. Guangdong Statistical Yearbook 2018; China Statistics Press: Beijing, China, 2018. (In Chinese)

55. Batty, M.; Longley, P. Fractal Cities: A Geometry of Form. and Function; Academic Press: London, UK, 1994; pp. 42-49.

56. Benguigui, L.; Czamanski, D.; Marinov, M.; Portugali, Y. When and where is a city fractal? Environ. Plan. B 2000, 27, 507-519. [CrossRef]

57. Chen, Y.G.; Jiang, S.G. Modeling fractal structure of systems of cities using spatial correlation function. Int. J. Artif. Life Res. IJALR 2009, 1, 12-34. [CrossRef]

58. Xu, J.H. Mathematical Methods in Contemporary Geography, 2nd ed.; Higher Education Press: Beijing, China, 2002. (In Chinese)

59. Gert, D.R. Environment conflicts in compact cities: Complexity, decision making and policy approaches. Environ. Plan. B 2000, 27, 151-162.

60. Ye, Y.Y.; Zhang, H.; Li, K.; Wu, Q.D. A research on the relationship between construction and expansion and the industrialization of the pearl river delta. Hum. Geogr. 2011, 26, 79-84. (In Chinese)

61. Camagni, R.; Cristina, M.; Rigamonti, P. Urban mobility and urban form: The social and environmental costs of different pattern of urban expansion. Ecol. Econ. 2002, 40, 199-216. [CrossRef]

62. Stephan, P.; Friedrich, D. Assessing the environmental performance of land cover types for urban planning. Landsc. Urban. Plan. 2001, 52, 1-20.

63. Leorey, O.M.; Nariida, C.S. A framework for linking urban form and air quality. Environ. Model. Softw. 1999, 14, 541-548.

64. Wang, X.S.; Liu, J.Y.; Zhang, D.F.; Wang, L.M. Spatial- temporal changes of urban spatial morphology in China. Acta Geogr. Sin. 2005, 60, 392-400. (In Chinese)

65. Brown, M.T.; Vivas, M.B. Landscape development intensity index. Environ. Monit. Assess. 2005, 101, $289-309$. [CrossRef] [PubMed]

66. Diggelen, R.; Sijtsma, F.J.; Strijker, D.; Burga, J. Relating land-use intensity and biodiversity at the regional scale. Basic Appl. Ecol. 2005, 6, 145-159. [CrossRef]

67. Zhu, H.X.; Pan, K.Y.; Liu, Y.; Chang, Z.; Jiang, P.; Li, Y.F. Analyzing Temporal and Spatial Characteristics and Determinant Factors of Energy-Related $\mathrm{CO}_{2}$ Emissions of Shanghai in China Using High-Resolution Gridded Data. Sustainability 2019, 11, 4766. [CrossRef]

68. Silverman, B.W. Using kernel density estimates to investigate multimodality. J. R. Statist. Soc. B 1981, 43, 97-99. [CrossRef]

69. Wang, J.; Zhang, W.W.; Zhang, Z.X. Quantifying the Spatio-Temporal Dynamics of Rural Settlements and the Associated Impacts on Land Use in an Undeveloped Area of China. Sustainability 2018, 10, 1490. [CrossRef]

70. He, C.F. Regional decentralisation and location of foreign direct investment in China. Post Communist Econ. 2006, 18, 33-50.

71. McDonald, J.F.; McMillen, D.P. Employment Subcenters and Land Values in a Polycentric Urban Area: The Case of Chicago. Environ. Plann. A 1990, 22, 1561-1574. [CrossRef]

72. Xu, X.Q.; Li, X. Review and preview of the urbanization in Pearl River Delta in the past 30 years of reform and opening up. Econ. Geogr. 2009, 29, 13-18. (In Chinese)

73. Fotheringham, A.S.; Brunsdon, C.; Charlton, M. Geographically Weighted Regression: The Analysis of Spatially Varying Relation-Ships; Wiley: Chichester, UK, 2002.

74. Rutherford, V.P. Global and local analysis of fragmentation in a mountain region of Colorado. Agric. Ecosyst. Environ. 2004, 101, 207-218. 
75. Yeh, G.O.; Yang, F.; Xu, Z.H. Will rural urbanization produce a new producer service space in China? Habitat Int. 2017, 67, 105-117. [CrossRef]

76. Gottmann, J. Megalopolis revisited: 25 years later; University of Maryland Institute for Urban Studies: College Park, MD, USA, 1987.

77. Dicken, P. Global shift; The Guilford Press: New York, NY, USA, 2011.

78. Dauth, W.; Suedekum, J. Globalization and local profiles of economic growth and industrial change. J. Econ. Geogr. 2016, 16, 1007-1034. [CrossRef]

79. Krugman, P. Development, Geography, and Economic Theory; The MIT Press: Cambridge, MA, USA, $1995 ;$ p. 117.

80. Hall, P.G. The World Cities; Heinemann: London, UK, 1966.

81. Hall, P.G. Global City-Regions in the Twenty-first Century. In Global City-Regions: Trends, Theory, Policy; Scott, A.J., Ed.; Oxford University Press: Oxford, UK, 2001; pp. 59-77.

82. Lampard, E.E. The history of cities in the economically advanced areas. In Regional Development and Planning; Friedmann, J., Alonso, W., Eds.; The MIT Press: Cambridge, MA, USA, 1964.

(C) 2019 by the authors. Licensee MDPI, Basel, Switzerland. This article is an open access article distributed under the terms and conditions of the Creative Commons Attribution (CC BY) license (http://creativecommons.org/licenses/by/4.0/). 